\title{
Designing Highly Stable Poly(sarcosine)-based Telodendrimer Micelles with High Drug Content Exemplified with Fulvestrant
}

Qing $\mathrm{Yu}^{1}$, Richard M. England ${ }^{1 *}$, Anders Gunnarsson ${ }^{2}$, Robert Luxenhofer ${ }^{4,5}$, Kevin Treacher $^{3}$, Marianne B. Ashford ${ }^{1}$

\footnotetext{
${ }^{1}$ Advanced Drug Delivery, Pharmaceutical Sciences, R\&D, AstraZeneca, Macclesfield, SK10 2NA, UK

${ }^{2}$ Discovery Sciences, R\&D, AstraZeneca, Gothenburg, 431 50, Sweden

${ }^{3}$ New Modalities and Parenterals Development, Pharmaceutical Technology and Development, Operations, AstraZeneca, Macclesfield, SK10 2NA, UK

${ }^{4}$ Functional Polymer Materials, Institute for Functional Materials and Biofabrication, Department of Chemistry and Pharmacy, Würzburg University, Röntgenring 11, 97070 Würzburg, Germany

${ }^{5}$ Soft Matter Chemistry, Department of Chemistry and Helsinki Institute of Sustainability Science, Faculty of Science, University of Helsinki, 00014 Helsinki, Finland
} 


\begin{abstract}
Polymeric micelles have been extensively used as nanocarriers for the delivery of chemotherapeutic agents aiming to improve their efficacy in cancer treatment. However, poor loading capacity, premature drug release, non-uniformity and reproducibility still remain the major challenges. To create a stable polymeric micelle with high drug loading, a telodendrimer micelle was developed as a nanocarrier for fulvestrant, as an example of a drug that has extremely poor water solubility (sub nanomolar range). Telodendrimers were prepared by synthesis of a hydrophilic linear poly(sarcosine) and growing a lysine dendron from the chain terminal amine by a divergent synthesis. At the periphery of the dendritic block, 4, 8, and 16 fulvestrant molecules were conjugated to the lysine dendron creating a hydrophobic block. Having drug as part of the carrier not only reduces the usage of the inert carrier materials but also prevent the drugs from leakage and premature release by diffusion. The self-assembled telodendrimer micelles demonstrated good colloidal stability $(\mathrm{CMC}<2 \mu \mathrm{M})$ in buffer and were uniform in size. In addition, these telodendrimer micelles could solubilize additional fulvestrant yielding an excellent overall drug loading capacity of up to $77 \mathrm{wt} . \%$ total drug load (summation of conjugated and encapsulated). Importantly, the size of the micelles could be tuned between 25-150 $\mathrm{nm}$ by controlling (i) the ratio between hydrophilic and hydrophobic blocks and (ii) the amount of encapsulated fulvestrant. The versatility of these telodendrimer-based micelle systems to both conjugate and encapsulate drug with high efficiency and stability, in addition to possessing other tuneable properties makes it a promising drug delivery system for a range of active pharmaceutical ingredients and therapeutic targets.
\end{abstract}




\section{INTRODUCTION}

Polymeric micelles have served as highly promising platforms for the delivery of chemotherapeutic agents over the past three decades. ${ }^{1}$ Chemotherapeutic agents often exhibit high toxicity and poor solubility which lead to a reduction in efficacy for cancer treatment. Micelles that are self-assembled from amphiphilic block copolymers (BCPs) and used as drug delivery systems can encapsulate hydrophobic drug molecules in the core whilst maintaining a hydrophilic corona on the surface providing high aqueous solubility and can control systemic exposure of the drug, reducing toxicity. ${ }^{2-3}$ However, problems including low drug loading capacity and efficiency, poor colloidal stability in the bloodstream and rapid clearance, as well as non-uniform micelle size $\mathrm{e}^{4-5}$ still remain major challenges for the development of an effective micelle for drug delivery. ${ }^{6-7}$ Physicochemical properties of a micelle such as shape, size, and surface chemistry have been reported to affect cell uptake, tumour penetration, and blood circulation time and have been identified as important determinants for the successful delivery of chemotherapeutic agents. ${ }^{8-11}$

The release of drugs from polymeric micelles is mainly affected by factors such as the diffusion coefficient of the drug, and the micelle's colloidal stability. ${ }^{12}$ Micelle formulations undergo a large volume dilution following intravenous (i.v.) administration. When reaching a concentration below the critical micelle concentration (CMC), micelles should disassemble which should lead to increased drug release, unless they are kinetically trapped. This premature release of drug severely impacts the therapeutic performance of the drug delivery system. ${ }^{6,13}$ Although various types of micelles have been used in drug delivery, a system that can offer high levels of control over stability is still highly desirable. ${ }^{14}$ From the extensive studies on polymeric micelles, researchers have identified the key factor that influences stability is the chemical composition of the core- and corona-forming blocks. Stability can be improved by increasing hydrophobic chain length and the degree of hydrophobicity. For example, Kabanov's group prepared a series of Pluronic micelles from block copolymers that differ in the lengths of the hydrophilic ethylene oxide (EO) and hydrophobic propylene oxide (PO) blocks. They found copolymers with higher content of hydrophobic block form micelles at lower concentration, i.e. exhibiting smaller CMC values. ${ }^{15}$ Adams et al. synthesized poly(ethylene oxide)-block-poly(N-hexyl-L-aspartamide) acyl conjugates with increasing acyl chain length on the hydrophobic block to form micelles. The increased side chain led to a similar reduction in CMC and resulted in more stable micelles. ${ }^{16-17}$ Wishart's group investigated the effect of core hydrophobicity on micelle stability using some poly(ethylene 
oxide)-block-peptide BCPs with different peptide sequences. Their findings suggested that BCPs synthesized from more aliphatic and aromatic peptides such as PEO- $b$ poly(phenylalanine) formed micelles of lower CMC values compared to those from PEO- $b$ poly(tyrosine). ${ }^{18}$ This improvement in stability was a result of both increased hydrophobicity and $\pi$ - $\pi$ stacking interaction in the core. Other than $\pi$ - $\pi$ stacking, ${ }^{19}$ hydrogen-bonding ${ }^{20}$ and donor-acceptor coordination ${ }^{21}$ have also been used to enhance core-drug interaction in order to improve micelle stability. Apart from micelle stability, the drug loading capacity and the increase of apparent drug concentration in the micelle can be considered as critical factors. Most drug delivery platforms, including polymeric micelles are often limited by drug loadings of less than $20 \mathrm{wt} . \%$ which can limit their applications as drug nanocarriers. ${ }^{22}$ Increasing the hydrophobicity and binding affinity between the hydrophobic core-forming block and drugs has often been suggested to achieve high loading capacity. ${ }^{7}$ On the other hand, some of the highest drug loadings for polymer micelles (exceeding $50 \mathrm{wt} \%$ ) have been reported using amphiphilic block copolymers ${ }^{23-25}$ which have a minimal amphiphilic contrast or do not even form micelles in the absence of a drug. ${ }^{26}$ Apart from drug formulations, polymer-drug conjugates (polymer prodrugs) are a popular alternative to cope with poorly soluble drugs and/or uncontrolled drug release. An interesting combination of both approaches is the use of polymer micelles that self-assemble from polymer-drug conjugates for the solubilization of additional drug. These usually exhibit a high loading capacity contributed from both physically encapsulated drugs and covalently conjugated drugs. For instance, Allen and co-workers prepared docetaxel-loaded micelles from both poly(ethylene glycol)-block-poly( $\varepsilon$ caprolactone) (PEG- $b$-PCL) and docetaxel (DTX) conjugated PEG- $b$-PCL(2k1k)-DTX. ${ }^{27}$ The conjugated micelles showed up to $9.2 \mathrm{mg} / \mathrm{mL}$ DTX at a PEG-b-PCL(2k1k)-DTX concentration of $30 \mathrm{mg} / \mathrm{ml}$, equivalent to an 1840-fold increase in aqueous solubility of DTX and the CMC of the PEG- $b$-PCL was reduced from 20.6 to $14.0 \mathrm{mg} / \mathrm{L}$ following the conjugation of DTX.

Here, a poly(sarcosine)- $b$-poly(L-lysine) based telodendrimer micelle is reported for the first time. Linear poly(sarcosine) (PSar) was polymerized from a primary amine initiator, and a poly(L-lysine) (PLL) dendron was divergently synthesized from the PSar chain terminal amino group. The resulting telodendrimer provided multiple functional sites at the dendritic ends for drug conjugation. Moreover, the linear-dendritic structure has been previously reported to provide enhanced core hydrophobicity to increase micelle stability as well as drug loading. ${ }^{28-29}$ These telodendrimers were found to form uniform micelles in water via the cosolvent evaporation method. ${ }^{22,30}$ The conjugated fulvestrant on the telodendrimer formed the 
hydrophobic core and was capable of encapsulating further fulvestrant. A series of micelles with controlled size ( 25 to $150 \mathrm{~nm}$ ) and narrow size distribution were prepared by varying telodendrimer generation and drug feeding concentrations. Importantly, the conjugation of fulvestrant to the dendritic core-forming block not only increased the loading capacity of the encapsulated drug, but also minimized the drug release caused by diffusion. In combination with the good solubility and colloidal stability in water, these telodendrimers demonstrated great potential as nanocarriers for the delivery of fulvestrant.

\section{MATERIALS AND METHODS}

All reagents were purchased from Sigma-Aldrich unless stated otherwise. Z-Sar-OH was purchased from Fluorochem Ltd. Boc-L-Lys(Boc)-ONp was purchased from Chem-Impex International. Tert-butyl hydrogen succinate was purchased from Alfa-Aesar. 4-(4,6Dimethoxy-1,3,5-triazin-2-yl)-4-methylmorpholinium tetrafluoroborate (DMTMM-BF 4 ) was synthesized as previously reported. ${ }^{31}$ Sarcosine N-carboxyanhydride (NCA) was supplied from WuXi AppTec and further purified by crystallization from EtOAc/heptane prior to use.

\section{Instrumentation}

Nuclear Magnetic Resonance. ${ }^{1} \mathrm{H}$ NMR experiments were performed on a Bruker UltraShield AVIII $500 \mathrm{MHz}$ spectrometer fitted with a QCI cryoprobe. All the measurements were conducted at room temperature using an acquisition time of 12 seconds and a delay time of 77 seconds to allow the full capture of polymer signals. Spectra were analysed using MestReNova version 9.0.

Multi Detector Size Exclusion Chromatography (MD-SEC). Size exclusion chromatography (SEC) was performed on a Malvern Panalytical OMNISEC system using two PSS Novema Max columns $(100 \AA(10 \mu \mathrm{m})+30 \AA(5 \mu \mathrm{m}))$ in series with an aqueous eluent of $100 \mathrm{mM} \mathrm{NaCl}+0.1 \mathrm{v} / \mathrm{v} \%$ TFA. The system was calibrated using a single PEO narrow standard $(24 \mathrm{kDa}, \mathrm{dn} / \mathrm{dc}=0.132)$ and absolute molar masses were determined using the refractive index (RI) and light scattering signals. Samples were prepared at $2-5 \mathrm{mg} / \mathrm{mL}$ and analyzed using OMNISEC software version 11.0.

Matrix-Assisted Laser Desorption/Ionization Time of Flight Mass Spectrometry. MALDITOF was performed on a Bruker UltrafleXtreme using the built-in method LP_5-20kDa. Samples were prepared at $5 \mathrm{mg} / \mathrm{mL}$ in methanol. A 1:1 (v/v) mixture of matrix solution and sample solution were spotted onto an MTP 384 polished steel target plate $(1 \mu \mathrm{L}$, twice per spot). $\alpha$-CHCA matrix solution (saturated in 50\% ACN/0.1\% aqueous TFA) was used for linear PSar 
and super-DHB matrix solution (40 mg/mL in THF) was used for telodendrimers. Spectra were recorded using Bruker flexControl software version 3.4 and analyzed by Bruker flexaAnalysis software version 3.4.

Dynamic Light Scattering. A Malvern Zetasizer® Ultra instrument equipped with multiangle detector $\left(173^{\circ}, 13^{\circ}\right.$, and $\left.90^{\circ}\right)$ and He-Ne laser at wavelength $633 \mathrm{~nm}$ was used for both size measurement and CMC determination. The dispersant RI and viscosity of water were used ( $n=1.59$ and $\eta=0.888 \mathrm{mPa} \cdot \mathrm{s}$ ). Samples were filtered through a $0.45 \mu \mathrm{m}$ PVDF syringe filter prior to measurement. All the experiments were conducted at $25{ }^{\circ} \mathrm{C}$ in triplicate, using three individually prepared samples and results are presented as mean \pm standard deviation (SD). Data were obtained using ZS XPLORER software version 1.0.

Mass Photometry. Mass photometry was performed on a Refeyn One mass photometry instrument (Refeyn Ltd, UK). All the micelle samples were diluted to $4 \mu \mathrm{g} / \mathrm{mL}$ in HBS-N (10 $\mathrm{mM}$ HEPES, $150 \mathrm{mM} \mathrm{NaCl}, \mathrm{pH}=7.4$ ) and analyzed using $60 \mathrm{~s}$ acquisition time. Peak contrast was calculated from the resulting histograms using Gaussian fits. As scattering signal scales with polarizability, which is a function of refractive index and proportional to particle volume, the contrast-to-mass conversion was achieved using a native protein ladder with known species of different sizes (NativeMark, ThermoFisher). Despite differences in refractive index between proteins $(\mathrm{dn} / \mathrm{dc} \sim 0.185)$ and PSar star polymers $(\mathrm{dn} / \mathrm{dc} \sim 0.16)$, previous characterization of PSar star polymers using MP have shown that masses obtained for the star polymers are in good agreement with both MD-SEC and MALDI-TOF-MS. ${ }^{32}$

\section{Methods}

\section{Synthesis of linear poly(sarcosine)}

Sarcosine NCA (2.16 g, $18.2 \mathrm{mmol})$ was fully dissolved in $12 \mathrm{~mL}$ of anhydrous DMF under nitrogen protection. The initiator 2-methoxyl ethyl amine $(16 \mu \mathrm{L}, 0.183 \mathrm{mmol})$, dissolved in $1 \mathrm{~mL}$ of DMF was added rapidly to the monomer solution via a syringe. The reaction mixture was stirred for $4 \mathrm{~h}$ at room temperature with nitrogen flow. The solution was slowly added to a rapidly stirring tert-butyl methyl ether (TBME) (200 mL) to form a precipitate. The precipitate was collected via vacuum filtration and dried overnight at $40{ }^{\circ} \mathrm{C}$ in a vacuum oven. Yield $1.27 \mathrm{~g}, 96.4 \%$. GPC see Figure $1 .{ }^{1} \mathrm{H}$ NMR see Figure S1 in ESI. Molecular weight data see Table 1.

Synthesis of poly(sarcosine)-b-poly(L-lysine) telodendrimer PSar $100-b-P L L\left[N H_{2} . T F A\right]_{n}{ }^{G m}$ 
A series of amide coupling reactions were employed to generate poly(sarcosine)-b-poly( L-lysine) telodendrimer PSar ${ }_{100}-b-\mathrm{PLL}\left[\mathrm{NH}_{2} \text {.TFA }\right]_{\mathrm{n}}{ }^{\mathrm{Gm}}$ of desired generation. The $1^{\text {st }}$ generation PSar $_{100-} b$-PLL[NH.Boc $]_{2}{ }^{\mathrm{G} 1}$ was prepared by coupling Boc-L-Lys(Boc)-ONp (120 mg, 0.254 mmol, 2 equiv.) on to the $N$-terminus of linear PSar $100(850 \mathrm{mg}, 0.118 \mathrm{mmol})$ in anhydrous DMF $(5 \mathrm{~mL})$. The reaction mixture was stirred for $4 \mathrm{~h}$ under nitrogen protection and then slowly added to a rapidly stirring TBME $(200 \mathrm{~mL})$ to form a precipitate. The solid was collected via vacuum filtration and dried overnight at $40{ }^{\circ} \mathrm{C}$ in a vacuum oven. Yield $846 \mathrm{mg}$, $95.2 \%$. To remove the Boc protecting group, $\operatorname{PSar}_{100}-b$-PLL[NH.Boc $]_{2}{ }^{\mathrm{G} 1}(820 \mathrm{mg})$ was dissolved in $8 \mathrm{~mL}$ DCM/TFA (1:1 by volume) and stirred for $2 \mathrm{hr}$ at room temperature under nitrogen. The reaction mixture was added dropwise to a rapidly stirring TBME (200 $\mathrm{mL})$ to precipitate. The resulting $\operatorname{PSar}_{100}-b-\mathrm{PLL}\left[\mathrm{NH}_{2} \cdot \mathrm{TFA}\right]_{2}{ }^{\mathrm{G} 1}$ was collected via vacuum filtration and dried overnight at $40{ }^{\circ} \mathrm{C}$ in a vacuum oven. Yield $817 \mathrm{mg}, 99.2 \%$. The $2^{\text {nd }}$ to $4^{\text {th }}$ generation $\mathrm{PSar}_{100}-b-\mathrm{PLL}\left[\mathrm{NH}_{2} . \mathrm{TFA}\right]_{\mathrm{n}}{ }^{\mathrm{Gm}}$ telodendrimers were prepared following the same method.

\section{Synthesis of fulvestrant succinate}

Fulvestrant (100 mg, $0.16 \mathrm{mmol}$ ) was added to a $25-\mathrm{mL}$ round bottom flask and dissolved in $3 \mathrm{~mL}$ anhydrous DCM under nitrogen, followed by the addition of triethylamine (TEA) (2 equiv.), 4-dimethylaminopyridine (20 mg, $0.16 \mathrm{mmol}), \mathrm{EDC} \cdot \mathrm{HCl}(80 \mathrm{mg}, 0.4 \mathrm{mmol})$, and tertbutyl hydrogen succinate $(30 \mathrm{mg}, 0.17 \mathrm{mmol})$. The reaction was left to stir at room temperature and followed to completion by UPLC-MS (approximately $1 \mathrm{hr}$ ). The reaction mixture was diluted with DCM (20 mL) and washed with $0.2 \mathrm{M} \mathrm{HCl} \mathrm{(20} \mathrm{mL,} \mathrm{twice)} \mathrm{followed} \mathrm{by} \mathrm{brine} \mathrm{(20}$ $\mathrm{mL})$. The organic layer was dried over magnesium sulfate. The solvent was removed under vacuum and yielded $112 \mathrm{mg}, 89 \%$ fulvestrant t-butyl succinate. To remove the tert-butyl ester protecting group, TFA/DCM ( $3 \mathrm{~mL}, 1: 1$ by volume) were added to fulvestrant t-butyl succinate and stirred under nitrogen for $2 \mathrm{~h}$. The excess solvent and t-butyl alcohol by-product were removed by rotary evaporation. The product fulvestrant succinate was obtained as a clear oily liquid, yield $96 \mathrm{mg}, 92.5 \%$. For ${ }^{1} \mathrm{H}$ NMR spectra, see Figure S2.

Synthesis of fulvestrant conjugated telodendrimer PSar $100-b-P L L[F L V]_{8}^{G 3}$ (TD-FLV8)

Fulvestrant succinate $(96 \mathrm{mg}, 0.136 \mathrm{mmol})$ and 4-(4,6-dimethoxy-1,3,5-triazin-2-yl)-4methyl-morpholin-4-ium (71 mg, $0.216 \mathrm{mmol}$ ) were added to a $10-\mathrm{mL}$ round bottom flask and completely dissolved in $1 \mathrm{~mL}$ anhydrous DMF. In a separate vial, $\operatorname{PSar}_{100}-b-\mathrm{PLL}\left[\mathrm{NH}_{2} . \mathrm{TFA}\right]_{8}^{\mathrm{G} 3}$ (112 $\mathrm{mg}, 0.0125 \mathrm{mmol}$ ) was dissolved in $1.5 \mathrm{~mL}$ anhydrous DMF. After adjusting the $\mathrm{pH}$ to $\sim 8$ using TEA, PSar ${ }_{100}-b$-PLL $\left[\mathrm{NH}_{2} \text {. TFA }\right]_{8}{ }^{\mathrm{G} 3}$ solution was transferred to the mixture and stirred at room temperature for $3 \mathrm{hr}$. The reaction mixture was slowly added to rapidly stirring TBME 
$(100 \mathrm{~mL})$ to form a precipitate. The precipitate was collected and purified by centrifugation (3900 g, 5 min, repeated 3 times) to give a white solid. The solid was dried overnight under vacuum at $40{ }^{\circ} \mathrm{C}$. Yield $111 \mathrm{mg}, 67.1 \%$.

PSar $_{100}-b$-PLL[FLV $]_{4}{ }^{\mathrm{G} 2}$ (TD-FLV4) was prepared using the same method. Reagent quantities: fulvestrant succinate (800 mg, $1.0 \mathrm{mmol})$, 4-(4,6-dimethoxy-1,3,5-triazin-2-yl)-4methyl-morpholin-4-ium (450 mg, $1.372 \mathrm{mmol}$ ), PSar ${ }_{100}-b-\mathrm{PLL}\left[\mathrm{NH}_{2} . \mathrm{TFA}\right]_{4}{ }^{\mathrm{G} 2}$ (400 mg, $0.0366 \mathrm{mmol}$ ), and $7 \mathrm{~mL}$ anhydrous DMF. Yield $583 \mathrm{mg}, 79.2 \%$.

$\operatorname{PSar}_{100}-b-\mathrm{PLL}[\mathrm{FLV}]_{16}{ }^{\mathrm{G} 4}$ (TD-FLV16) was prepared using the same method. Reagent quantities: fulvestrant succinate (140 mg, $0.158 \mathrm{mmol}), 4$-(4,6-dimethoxy-1,3,5-triazin-2-yl)4-methyl-morpholin-4-ium (76 mg, $0.231 \mathrm{mmol})$, PSar ${ }_{100}-b$-PLL[NH $\mathrm{N}_{2}$.TFA $]_{16}{ }^{\mathrm{G} 4}$ (151 mg, $0.0188 \mathrm{mmol}$ ), and $2 \mathrm{~mL}$ anhydrous DMF. Yield $182 \mathrm{mg}, 93.7 \%$.

\section{Preparation of telodendrimer micelles}

Both blank and drug-encapsulating telodendrimer micelles were prepared by co-solvent evaporation method. A unimer solution was prepared by dissolving the telodendrimer and various amount of fulvestrant (drug feeding of 0 to $50 \mathrm{wt} . \%$ ) in acetone to give a final concentration of $20 \mathrm{mg} / \mathrm{mL}$. The unimer solution was added dropwise to an equal volume of water. The mixture solution was stirred briefly for $5 \mathrm{~min}$ and then the acetone was evaporated under nitrogen using a Smart Evaporator (BioChromato, Japan). The complete removal of acetone was monitored by ${ }^{1} \mathrm{H}$ NMR. The resulting micelle solutions were filtered through a $0.45 \mu \mathrm{m}$ filter to remove any larger aggregates. Quantification of fulvestrant was conducted using ${ }^{1} \mathrm{H}$ NMR (Figure S7-S10). Telodendrimer and fulvestrant were weighed out at each planned feeding ratio and dissolved in $d$-acetic acid for proton NMR measurements to determine the integrations of conjugated fulvestrant and free fulvestrant. After drug encapsulation, the filtered micelle solutions were freeze dried and re-dissolved in $d$-acetic acid for proton NMR measurements to determine the amount of encapsulated fulvestrant, using the conjugated fulvestrant as internal reference. A purity check by proton NMR for TD-FLV8 telodendrimer was performed using maleic acid as reference standard in order to accurately determine the feeding fractions for each fulvestrant-encapsulating micelles (Figure S7).

The drug encapsulation efficiency (EE\%) and loading capacity (LC\%) were calculated using the following equations:

$\mathrm{EE} \%=\frac{m_{\text {drug }}}{m_{\text {drug added }}} \times 100 \%$ 
$\mathrm{LC} \%=\frac{m_{\text {drug }}}{m_{\text {polymer }}+m_{\text {drug }}} \times 100 \%$

where $m_{\text {drug }}$ and $m_{\text {polymer }}$ are the weights of the drug and telodendrimer in the micelle, and $\mathrm{m}_{\text {drug,added }}$ is the initial mass of the drug added.

The total drug loading capacity including both chemically conjugated and physically encapsulated drugs was calculated using the following equation:

$\mathrm{LC}_{\text {total }} \%=\frac{m_{\text {drug }}+x \times m_{\text {polymer }}}{m_{\text {polymer }}+m_{\text {drug }}} \times 100 \%$

where $x$ is the wt. $\%$ of the conjugated fulvestrant in each telodendrimer as shown in Table 3 .

\section{CMCs of telodendrimer micelles}

The CMCs of both blank and drug-encapsulating micelles in PBS buffer were estimated by dynamic light scattering. The micelle samples were prepared by serial dilution and concentration varied from 0.01 to $100 \mu \mathrm{g} / \mathrm{mL}$. The intensity of scattered light in kilo-counts per second (kcps) was measured using a fixed attenuator at 11 for all the micelle solutions. To determine the CMC, the intensity was plotted against concentration and the intersection of the two slopes indicated the onset of micellization.

\section{Hydrolysis-induced drug release from the micelles}

The release of fulvestrant from blank TD-FLV8 micelles was performed at $37{ }^{\circ} \mathrm{C}$ in PBS buffer at $\mathrm{pH} 5.5, \mathrm{pH} 7.4$, and $\mathrm{pH}$ 8.5. In addition, the effect of protein binding on drug release was tested at pH 7.4 using $45 \mathrm{mg} / \mathrm{mL}$ bovine serum albumin (BSA). Typically, $1 \mathrm{~mL}$ micelle solution $(2 \mathrm{mg} / \mathrm{mL})$ was incubated at $37{ }^{\circ} \mathrm{C}$ with gentle stirring. Fulvestrant released from the micelles precipitated in solution due to its poor solubility. Aliquots of $50 \mu \mathrm{L}$ were taken at various time points and then mixed with $50 \mu \mathrm{L}$ acetonitrile to completely solubilize the released fulvestrant. To ensure the drug was suspended homogenously, the solution was sonicated for 5 min before taking each aliquot. The amount of drugs released was assessed by UPLC using a standard calibration curve of fulvestrant as shown in Figure S13. The percentage of drug release from telodendrimer micelles were summarized in Table S1.

\section{RESULTS AND DISCUSSION}

\section{Preparation and Characterization of PSar ${ }_{100}-b-P L L\left[\mathrm{NH}_{2} . \mathrm{TFA}\right]_{n}{ }^{\mathrm{Gm}}$ Telodendrimer.}

A telodendrimer is an amphiphilic block copolymer that has a linear block and a dendritic block. $^{33}$ Its unique linear-dendritic structure has demonstrated enhanced polymer-drug interactions, making the telodendrimer micelle a very promising nanocarrier for drugs. ${ }^{28}$ Some 
PEG-containing telodendrimer micelles have been used to encapsulate insoluble drugs, however, achieving high loading capacity and uniform micelle size have always been challenging. ${ }^{28-29,34}$ Here, a PSar-based telodendrimer micelle system was specifically designed for the poorly soluble fulvestrant, an oestrogen receptor antagonist that has been widely used to treat hormone receptor-positive metastatic breast cancer. Fulvestrant has extremely poor water solubility and is dosed as a sterile oily solution via intramuscular injection in order to give adequate bioavailability. ${ }^{35}$ Using telodendrimer micelle to deliver fulvestrant provides many advantages compared to traditional linear block copolymer micelles. For instance, the dendritic block in telodendrimer helps form well-defined architecture with narrow dispersity. Moreover, drugs can be loaded into the dendritic micelle core via both chemical conjugation and physical encapsulation to achieve high loading capacity. In the present design, a PSar homopolymer with a chain length of 100 repeat units was synthesized as the linear block and PLL dendrimers of various generations were grown from the chain end to form the dendritic block (Scheme 1). The corona-forming PSar is a promising replacement for the most widely used PEG due to its high hydrophilicity, biocompatibility and low antigenicity. ${ }^{36-39}$ PSar 100 was synthesized using nucleophilic ring-opening polymerization of sarcosine NCA using 2methoxyl ethyl amine as the initiator. The resulting polymer was fully characterized by ${ }^{1} \mathrm{H}$ NMR, MD-SEC, MALDI-TOF (Figure S1, Figure 1b and 1c), and its key properties are summarized in Table 1.

The terminal secondary amine of PSar was used as the focal point for the synthesis of the PLL dendritic block. Through a series of nucleophilic addition/elimination reactions using Boc- $L$-Lys(Boc)-ONp followed by Boc-deprotection, poly(sarcosine)- $b$-poly(L-lysine) $\left.\left(\mathrm{PSar}_{100}-b \text {-PLL[NH} \mathrm{NH}_{2} . \mathrm{TFA}\right]_{\mathrm{n}}{ }^{\mathrm{Gm}}\right)$ telodendrimers of the different generations could be synthesized (Table 1). As shown in Figure 1a, ${ }^{1} \mathrm{H}-\mathrm{NMR}$ analysis of the Boc-protected telodendrimer PSar ${ }_{100}-b$-PLL[NH.Boc $]_{\mathrm{n}}{ }^{\mathrm{Gm}}$ was used to confirm the full conversion (with the analytical limitation) of each generation when comparing the protons of the Boc groups on the dendritic block (1.47 ppm) to the $-\mathrm{CH}_{2}$ - signal (4.1-4.6 ppm) from the sarcosine repeat units. Trace amount of washing solvent TBME was left in the sample and showed two singlets at $3.30 \mathrm{ppm}$ and $1.25 \mathrm{ppm}$. Analysis of the $\mathrm{PSar}_{100}-b-\mathrm{PLL}\left[\mathrm{NH}_{2} \cdot \mathrm{TFA}\right]_{\mathrm{n}}{ }^{\mathrm{Gm}}$ telodendrimers by MDSEC and MALDI-TOF-MS (Figure 1b and 1c) yielded molar masses that were consistent with results obtained from ${ }^{1} \mathrm{H}-\mathrm{NMR}$. All of the telodendrimers prepared following this method exhibited narrow molar mass distributions $(Ð<1.10)$ and precise control over size and generation, i.e. number of amine end groups, and therefore sites for subsequent drug 
conjugation. The only exception is $\mathrm{PSar}_{100}-b$-PLL $\left[\mathrm{NH}_{2} \text {.TFA }\right]_{16}{ }^{\mathrm{G} 4}$ telodendrimer, whose molar mass determined by MD-SEC (Figure 1b) was lower compared with that obtained from ${ }^{1} \mathrm{H}-$ NMR and MALDI-TOF-MS. This lower apparent molecular weight suggested the $4^{\text {th }}$ generation telodendrimer experienced some degradation during the TFA deprotection.

(a)<smiles>COCCNC(=O)C[NH+](C)C</smiles>

(b)

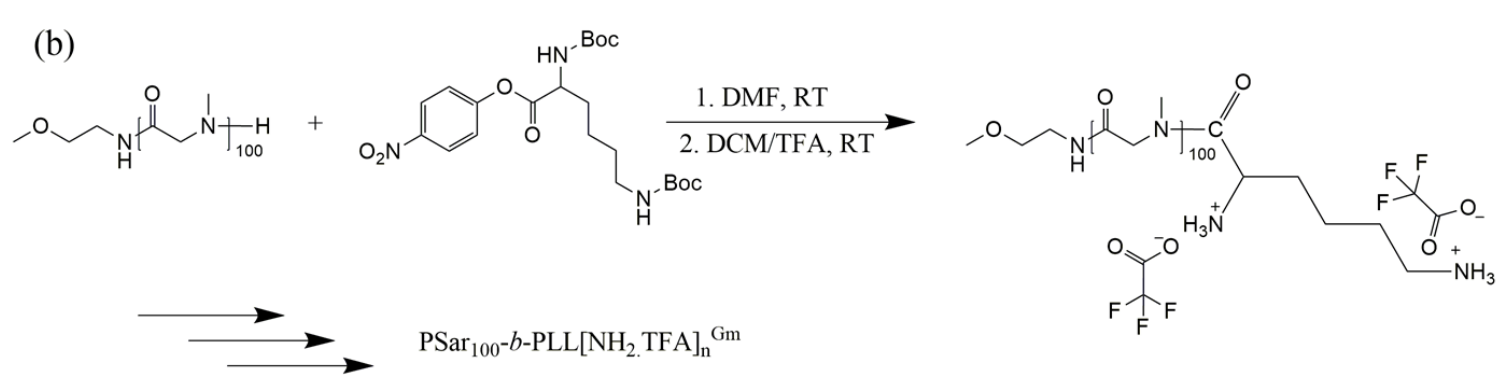

(c)

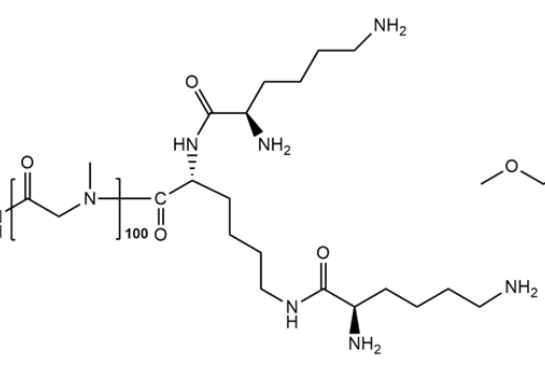

(d)

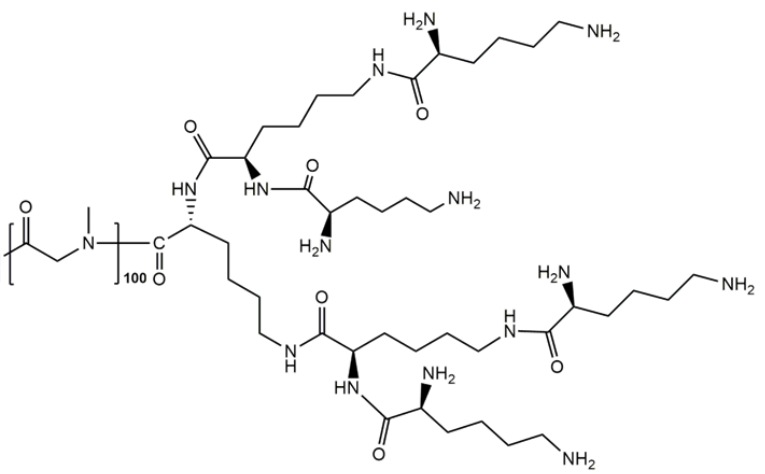

Scheme 1. Synthesis of (a) linear PSar and (b) telodendrimer of $\mathrm{m}^{\text {th }}$ generation that contains $n$ number of amines. Chemical structures of (c) $2^{\text {nd }}$ and (d) $3^{\text {rd }}$ generation telodendrimers.

Table 1. Characterization of PSar linear polymer and telodendrimers of different generations

\begin{tabular}{|c|c|c|c|c|}
\hline Samples & $\mathbf{M}_{\mathbf{n}}{ }^{\mathbf{a}}$ & $\mathbf{D}^{\mathbf{a}}$ & $\mathbf{D P}^{\mathbf{b}}$ & $\mathbf{M}_{\mathbf{P}}{ }^{\mathbf{c}}$ \\
\hline $\operatorname{PSar}_{100}$ & 7.1 & 1.01 & 100 & 6065 \\
\hline $\mathrm{PSar}_{100}-b$-PLL[NH$\left.{ }_{2} \cdot \mathrm{TFA}\right]_{2}{ }^{\mathrm{G} 1}$ & 5.8 & 1.05 & 106 & 6193 \\
\hline $\operatorname{PSar}_{100}-b-\mathrm{PLL}\left[\mathrm{NH}_{2} \cdot \mathrm{TFA}\right]_{4}{ }^{\mathrm{G} 2}$ & 6.9 & 1.05 & 88 & 6520 \\
\hline $\mathrm{PSar}_{100}-b-\mathrm{PLL}\left[\mathrm{NH}_{2} \cdot \mathrm{TFA}\right]_{8}{ }^{\mathrm{G} 3}$ & 7.0 & 1.08 & 98 & 7038 \\
\hline $\operatorname{PSar}_{100}-b-\mathrm{PLL}\left[\mathrm{NH}_{2} \cdot \mathrm{TFA}\right]_{16}{ }^{\mathrm{G} 4}$ & 6.8 & 1.15 & 90 & 7782 \\
\hline
\end{tabular}

${ }^{\mathrm{a}} \mathrm{MD}-\mathrm{SEC} \overline{(\mathrm{kDa}) .{ }^{\mathrm{b}} \text { Degree of polymerization from }{ }^{1} \mathrm{H} \text { NMR. }{ }^{\mathrm{c}} \text { Peak maximum } \mathrm{m} / \mathrm{z}}$ from MALDI-TOF. 

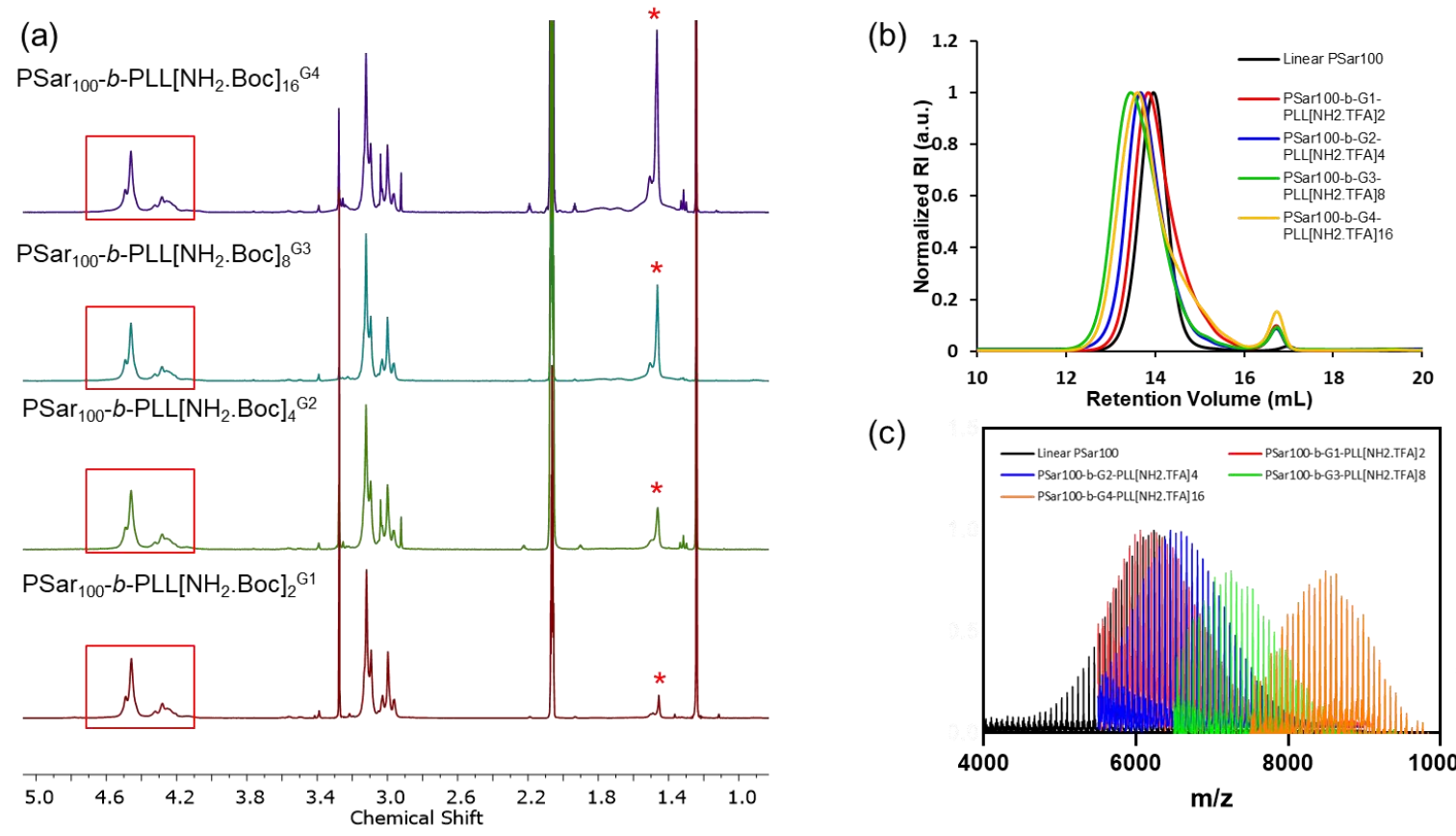

(c)

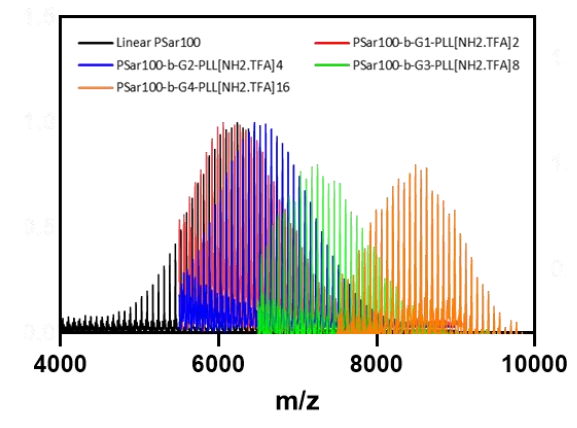

Figure 1. Characterization of PSar ${ }_{100}-b-\mathrm{PLL}\left[\mathrm{NH}_{2} . \mathrm{TFA}\right]_{\mathrm{n}}{ }^{\mathrm{Gm}}$ telodendrimers from G1 to G4. (a) ${ }^{1} \mathrm{H}$ NMR spectra $\left(d_{4} \text {-acetic acid) of PSar }{ }_{100}-b \text {-PLL[NH.Boc }\right]_{\mathrm{n}}{ }^{\mathrm{Gm}}$ telodendrimers highlighting signals from (*) Boc on the lysine dendron and ( $\square$ ) PSar (methylene groups). (b) Aqueous SEC chromatograms showing the normalized RI signals and (c) MALDI-TOF spectra from linear PSar $_{100}$ and PSar ${ }_{100}-b$-PLL[NH ${ }_{2}$.TFA $]_{\mathrm{n}}{ }^{\mathrm{Gm}}$ telodendrimers $\mathrm{G} 1$ to G4.

\section{Synthesis of fulvestrant-conjugated telodendrimer.}

To induce amphiphilicity in the telodendrimers, the hydrophobic drug molecule fulvestrant was conjugated to the amino groups at the periphery of the dendritic block. Fulvestrant was first modified by attachment of a succinic acid linker to enable direct conjugation to the telodendrimer lysine amines via amide coupling. The synthetic procedures employed for the preparation of fulvestrant-conjugated telodendrimer PSar $100-b$-PLL[FLV $]_{\mathrm{n}} \mathrm{Gm}$ $\left(\mathrm{TD}-\mathrm{FLV} \mathrm{V}_{\mathrm{n}}\right)$ are shown in Scheme 2.
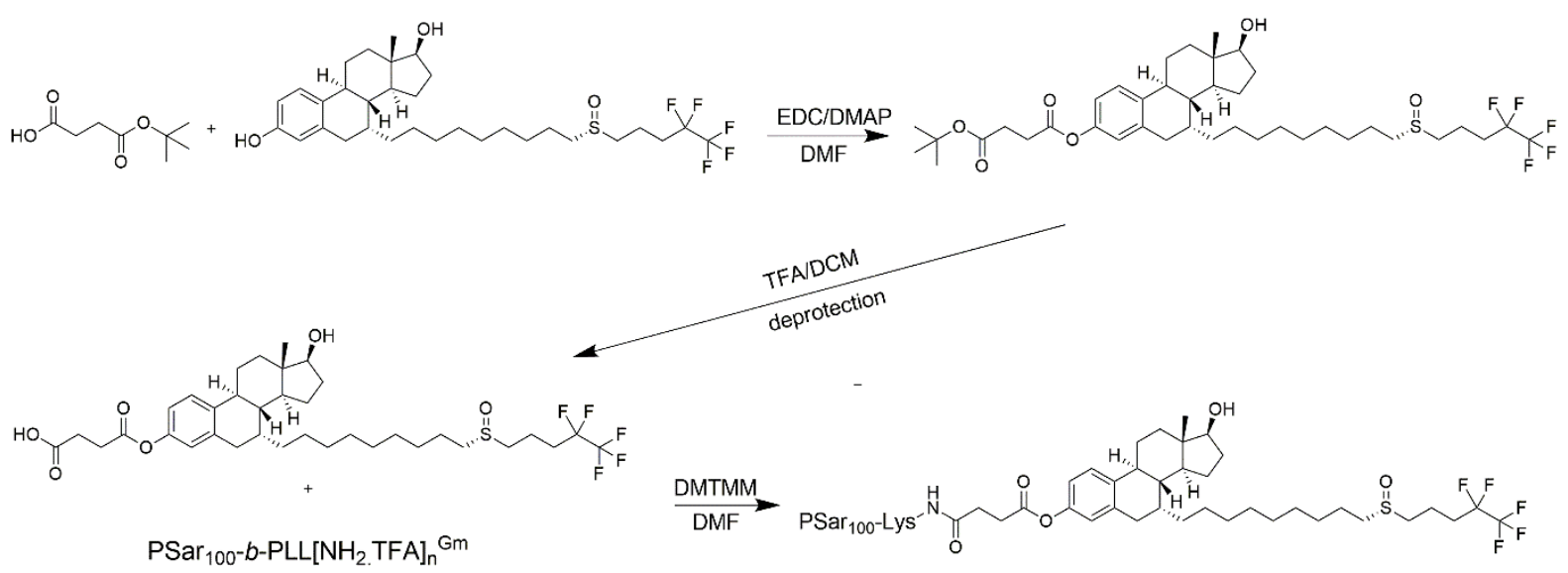

Scheme 2. Synthesis of fulvestrant succinate and conjugation to telodendrimer to form PSar ${ }_{100^{-}}$ $b$-PLL[FLV $]_{\mathrm{n}}^{\mathrm{Gm}}$. 
Fulvestrant has two hydroxyl groups at the 3 and 17 positions available for functionalization. Due to the increased reactivity and lower $\mathrm{pKa}$ of the phenol, the esterification with $t$-butyl succinate preferentially took place at the 3 position and yielded mono-substituted fulvestrant $t$-butyl succinate. The $t$-butyl protecting group was removed using TFA/DCM to yield fulvestrant succinate. As outlined in Figure S2, the disappearance of the singlet at 1.5 ppm in ${ }^{1} \mathrm{H}$ NMR spectra confirmed the complete removal of the $t$-butyl protecting group and left a carboxylic acid functional group available for conjugation to the telodendrimer. Figure 2 shows the chemical structure and ${ }^{1} \mathrm{H}-\mathrm{NMR}$ spectrum of a $3^{\text {rd }}$ generation fulvestrant-conjugated telodendrimer PSar ${ }_{100}-b$-PLL[FLV $]_{8}{ }^{\mathrm{G} 3}$ (TD-FLV8) with 8 fulvestrant molecules attached at the periphery of the dendritic block. Peaks $a\left(4.1-4.6 \mathrm{ppm}, 200 \mathrm{H}, \mathrm{CO}-\mathrm{CH}_{2}-\mathrm{N}\right)$ and $b(3.35 \mathrm{ppm}$, $3 \mathrm{H}, \mathrm{CH}_{3}-\mathrm{O}$ ) were assigned to the linear PSar block indicating a chain length of $\sim 100$ repeat units. The appearance of peaks $(d, e$, and $f)$ in the aromatic region confirmed the successful conjugation of fulvestrant to the telodendrimer. Ratios of fulvestrant to PSar were determined from the integration of peak e and peak $a$. On average, $\sim 6.5$ fulvestrant molecules were attached to each PSar chain. In addition to TD-FLV8, a $2^{\text {nd }}$ generation TD-FLV4 and a $4^{\text {th }}$ generation TD-FLV16 drug-conjugated telodendrimer were also synthesized and characterized following the same method (Figure S3) to carry 4 and 16 fulvestrant molecules at the dendritic block, respectively. MALDI-TOF-MS measurements were performed on TD-FLV4 and TD-FLV8 and confirmed the molecular weights of these drug-conjugated telodendrimers were consistent with the theoretical values (Figure S4). 


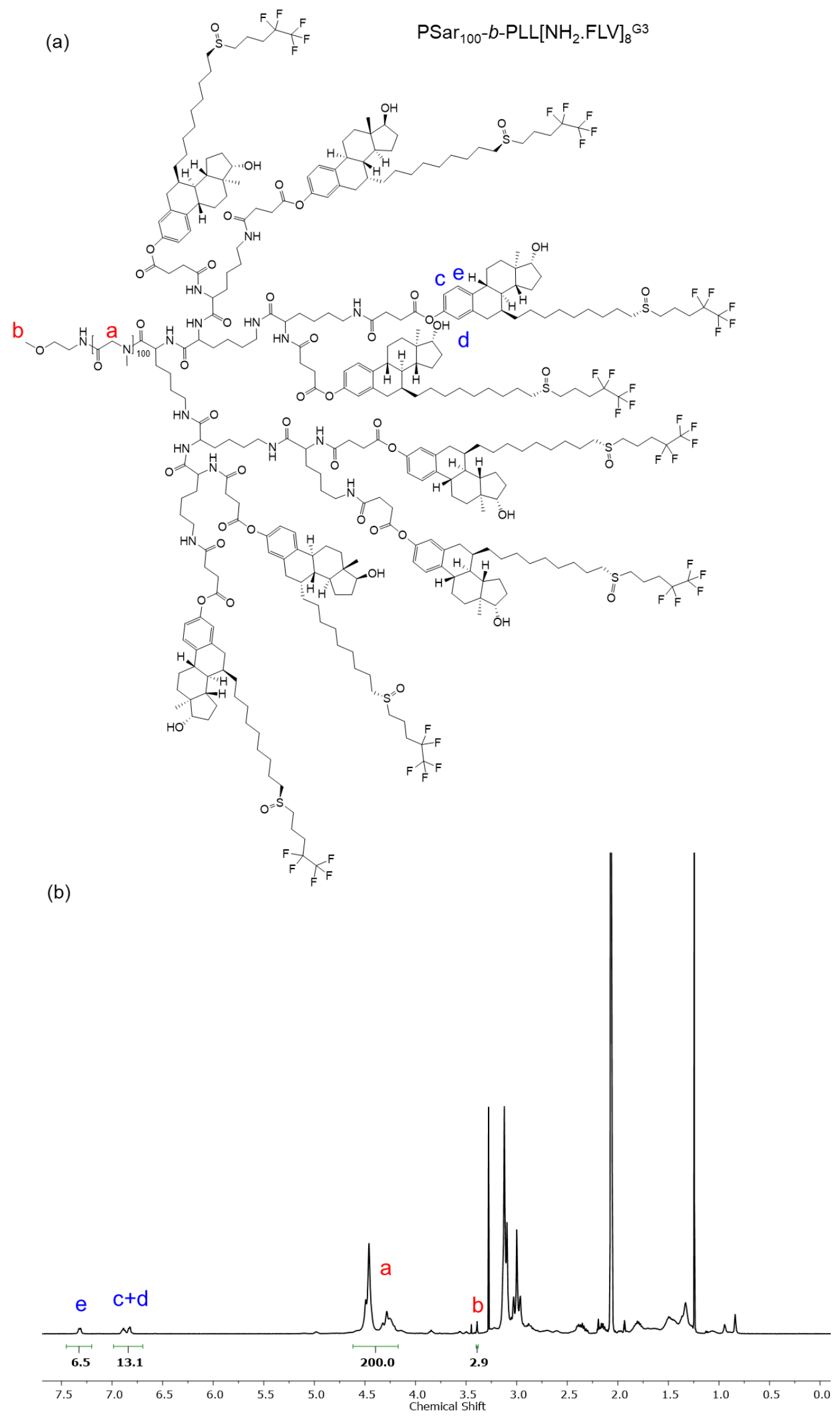

Figure 2. (a) Chemical structure of PSar ${ }_{100}-b$-PLL[FLV $]_{8}{ }^{\mathrm{G} 3}$ (TD-FLV8) and (b) ${ }^{1} \mathrm{H}$ NMR $(500 \mathrm{MHz}, \mathrm{d} 4-\mathrm{AcOH}, 300 \mathrm{~K})$ spectrum with corresponding peak assignments. 


\section{Self-assembly of fulvestrant-conjugated telodendrimers.}

Telodendrimer micelles were prepared in water from all TD-FLV $(n=4,8,16)$ samples by using a co-solvent evaporation method. ${ }^{22}$ The fulvestrant-conjugated telodendrimers were dissolved in acetone to prepare concentrated unimer solutions of $20 \mathrm{mg} / \mathrm{mL}$. The unimer solution was then slowly added to an equal volume of water with rapid stirring, followed by evaporation of the organic solvent under reduced pressure. The highly hydrophobic fulvestrant in the dendritic block triggered the formation of micelle to minimize the interfacial energy. The resulting micelles were characterized using dynamic light scattering (DLS) to obtain the average hydrodynamic size and polydispersity as summarized in Table 2 . The micelle sizes were found to depend on the telodendrimer generation. As the generations increased from 2 to 4 , the mass ratio of hydrophobic/hydrophilic blocks increased from 23/77 to 48/52. As shown in Figure 3a, the DLS results of the $2^{\text {nd }}$ generation TD-FLV4 micelle gave an average size of $25 \pm 0.8 \mathrm{~nm}$ with a polydispersity index (PDI) of 0.15 . As the number of fulvestrant molecules on the dendritic block increased from 4 to 8 , the $3^{\text {rd }}$ generation TD-FLV8 micelle exhibited a slightly larger size of $30 \pm 0.7 \mathrm{~nm}$ with PDI $=0.07$. A more significant increase to $116 \pm 2.8$ $\mathrm{nm}(\mathrm{PDI}=0.18)$ was observed for the $4^{\text {th }}$ generation TD-FLV16 micelle, with 16 fulvestrant molecules on the dendritic block. Interestingly, the change in size was much more significant in micelles formed from telodendrimers of high generations than those made of low generations. Only a $5 \mathrm{~nm}$ increase was observed when the number of fulvestrant molecules doubled from TD-FLV4 to TD-FLV8, whereas a 4 times increase in size was observed for TDFLV16 compared to TD-FLV8 micelles. This drastic increase in size might be a result of morphology change away from a simple micelle structure, which could be explained by the expansion of hydrophobic block volume in addition to the increased block length due to the presence of more fulvestrant molecules. Indeed preliminary CryoEM studies indicated these larger structures were polymersomes as shown in Figure S5. The changes in size caused by increasing the hydrophobic to hydrophilic block ratio were also found much more significant in telodendrimers than in linear block copolymers as the dendritic hydrophobic block is much more localised compared with the linear hydrophobic block of similar molecular weight. ${ }^{33,40}$

Another self-assembly method, thin-film dissolution was also explored to prepare TD$\mathrm{FLV}_{\mathrm{n}}$ micelles. Though it is a very commonly used technique for the formation of micelles, we only had limited success with TD-FLV4. Figure S6 includes the hydrodynamic size distributions of TD-FLV4 micelles prepared using co-solvent evaporation and thin-film methods. Larger structures of $56 \mathrm{~nm}$ with slightly higher polydispersity of 0.17 were obtained 
using the latter method. In the thin-film self-assembly experiments, when water was added to rehydrate the telodendrimer film, all three TD-FLV $\mathrm{n}_{\mathrm{n}}$ samples formed needle-like crystals in solution which were difficult to fully disperse even upon sonication. The re-hydrated solutions were left at room temperature for 1 week. Only the solution containing TD-FLV4 turned clear suggesting the formation of micelles as revealed by DLS, whereas TD-FLV8 and TD-FLV16 solutions still contained large precipitates at the bottom.

The difference between TD-FLV4 micelle size caused by different self-assembly pathways can be attributed in part to the different microenvironment the telodendrimers were exposed to during micelle formation. In the co-solvent evaporation method, the telodendrimer was dissolved in mixtures of organic and aqueous solvents and the organic solvent was then slowly removed. In this scenario, it is thought that the telodendrimers were given enough time to reach an equilibrium and form micelles from a homogenous starting point during the slow evaporation. Whereas in the thin-film approach, the hydrated telodendrimer film initially formed micelles, or much larger structures with broad size distribution and then underwent sonication to produce more uniform and smaller micelles. The telodendrimer chains are likely to have low mobility in aqueous solution due to the highly insoluble fulvestrant molecules on the dendritic block. Therefore, micelles formed in this way could not reach the thermodynamic equilibrium and resulted in larger sizes as well as broader size distributions. The difficulties in preparing TD-FLV8 and TD-FLV16 micelles using the thin-film approach could be explained using the same line of argument. As the number of fulvestrant molecules on the dendritic block increased to 8 and 16 , the solubility or mobility of these telodendrimers decreased drastically in aqueous solvent. Therefore the telodendrimers tended to form kinetically trapped agglomerates and precipitate by thin-film hydration.

\section{Encapsulation of additional fulvestrant using the TD-FLVn micelles}

Poor drug loading has been a major limitation in polymer micelle delivery systems and only few types of micelles can achieve a loading capacity $>20 \mathrm{wt} . \% .^{22-23,26,41-43}$ Since polymerdrug interaction is the driving force for the formation of drug encapsulated micelles, we hypothesize that using the drug itself as a binding moiety within the telodendrimer structure could provide the maximum interaction and thus lead to high loading. The fulvestrant molecule contains an aromatic head group with a long hydrocarbon chain as well as 2 hydrogen bond donors and 3 acceptors which can provide a $\pi$ - $\pi$ interaction, hydrophobic interaction and hydrogen bonding respectively. Moreover, the unique fluorophilic domain in fulvestrant molecule can probably drive the self-assembly in aqueous environment even further as it 
reduces self H-bonding and increases fluorocarbon self-assembly. The co-solvent evaporation method was employed to prepare drug encapsulated telodendrimer micelles. The fulvestrant loading capacity of TD-FLV $(n=4,8$, and 16) micelles was compared and summarized in Table 2. Similarly, to the preparation of blank micelles, TD-FLV $n$ was mixed with fulvestrant of various feeding concentrations to give a total concentration of $20 \mathrm{mg} / \mathrm{mL}$ in acetone. The telodendrimer/drug mixture solution was added to water of equal volume and formed micelles upon evaporation of organic solvent. Non-encapsulated fulvestrant was removed using a 0.45 $\mu \mathrm{m}$ syringe filter and the micelle solutions obtained were completely clear. ${ }^{1} \mathrm{H}$ NMR was used to determine both the drug loading capacity (LC) \% and encapsulation efficiency (EE) $\%$ of these micelles. Figure S8-S10 show the ${ }^{1} \mathrm{H}-\mathrm{NMR}$ spectra of TD-FLV $\mathrm{n}_{\mathrm{n}}$ micelles with their maximum loadings. The aromatic proton signals $(6.25-7.25 \mathrm{ppm})$ from fulvestrant broadened and shifted downfield when conjugated to the telodendrimer. Therefore, it was possible to integrate both conjugated and encapsulated drug and therefore calculate the amount of fulvestrant physically encapsulated in the micelle. Similarly, the encapsulation efficiency can be determined by comparing the amount of physically encapsulated fulvestrant before and after the self-assembly process. Detailed characterizations of these fulvestrant encapsulated micelles are summarized in Table 2 and Figure 3. The TD-FLV4 micelle showed a maximum loading capacity of $5 \mathrm{wt} . \%$ fulvestrant with a micelle size increase from 25 to $32 \mathrm{~nm}$. An EE of $98.8 \%$ was achieved for this micelle, multiple peaks were observed in the DLS, indicating a heterogenous size distribution. Fulvestrant loading capacity was found to increase with dendron generation. The $3^{\text {rd }}$ generation TD-FLV8 micelle had a maximum LC of $31 \mathrm{wt} . \%$ (EE $=98.0 \%$ ) while the $4^{\text {th }}$ generation TD-FLV16 micelle showed an even higher LC of $57 \mathrm{wt} . \%$ $(\mathrm{EE}=77.8 \%)$. In addition to the physically encapsulated drugs, there was also a contribution of drug loading from the covalently conjugated fulvestrant on dendritic block. Therefore, the maximum total drug contents for TD-FLV8 and TD-FLV16 were an impressive $57 \mathrm{wt} \%$ and 77 wt.\%, respectively.

The TD-FLV $\mathrm{n}$ self-assemblies also demonstrated excellent aqueous solubility. To find the maximum solubility of fulvestrant in water, a TD-FLV8 micelle solution was concentrated using a centrifugal spin-filter device with a $30 \mathrm{kDa}$ molecular weight cut-off membrane to obtain a final micelle concentration of $100 \mathrm{mg} / \mathrm{mL}$, whilst still being a fluid solution. However, the micelle solution became viscous at this point and was difficult to concentrate further. Fulvestrant has very poor solubility in water $(9.53 \mathrm{ng} / \mathrm{L}) .{ }^{44}$ However, using these telodendrimer 
micelles it was possible to increase the effective solubilization of the drug to $\sim 57 \mathrm{~g} / \mathrm{L}$ in water, which is a $\sim 10^{9}$-fold increase.

Table 2. Summary of characteristics and fulvestrant encapsulation data for different TD-FLV telodendrimer micelles

\begin{tabular}{|c|c|c|c|c|c|c|c|}
\hline Telodendrimer & $\begin{array}{l}\text { MWa } \\
(\mathbf{k D a})\end{array}$ & $\begin{array}{c}\text { Conjugated } \\
\text { FLV }^{\mathrm{a}} \\
(\text { wt.\%) } \\
\end{array}$ & $\begin{array}{l}\text { Size }^{b} \\
(\mathbf{n m})\end{array}$ & $\mathbf{P D I}^{\mathbf{b}}$ & $\mathrm{LC} \%^{\mathrm{c}}$ & EE\% ${ }^{c}$ & $\begin{array}{c}\mathbf{L C}_{\text {total }} \\
\%\end{array}$ \\
\hline \multirow[t]{2}{*}{$\begin{array}{c}\text { PSar }_{100-} b- \\
\mathrm{PLL}[\mathrm{FLV}]_{4}{ }^{\mathrm{G} 2}\end{array}$} & 10.3 & 23 & $25 \pm 0.8$ & 0.15 & - & - & 23 \\
\hline & & & multiple & $\mathrm{n} / \mathrm{a}$ & 5 & 98.8 & 27 \\
\hline \multirow[t]{5}{*}{$\begin{array}{c}\text { PSar }_{100-} b- \\
\text { PLL[FLV] }{ }_{8}^{\text {G3 }}\end{array}$} & 13.3 & 36 & $30 \pm 0.7$ & 0.07 & - & - & 36 \\
\hline & & & $40 \pm 0.5$ & 0.15 & $18 \pm 1.0$ & $99.6 \pm 4.3$ & 44 \\
\hline & & & $47 \pm 0.4$ & 0.09 & $28 \pm 0.8$ & $99.3 \pm 2.7$ & 51 \\
\hline & & & $53 \pm 3.8$ & 0.09 & $31 \pm 1.1$ & $98.0 \pm 4.9$ & 53 \\
\hline & & & $60 \pm 5.9$ & 0.08 & $37 \pm 1.7$ & $68.2 \pm 4.6$ & $57^{\mathrm{d}}$ \\
\hline \multirow[t]{3}{*}{$\begin{array}{c}\text { PSar }_{100-} b- \\
\text { PLL[FLV] }{ }_{16}{ }^{\mathrm{G} 4}\end{array}$} & 20.3 & 48 & $116 \pm 2.8$ & 0.18 & - & - & 48 \\
\hline & & & $140 \pm 1.8$ & 0.13 & 40 & 63.5 & 69 \\
\hline & & & $150 \pm 4.5$ & 0.12 & 56 & 77.8 & 77 \\
\hline
\end{tabular}

a Theoretical molecular weight and conjugated drug content. ${ }^{\mathrm{b}}$ Hydrodynamic diameter and polydispersity index (PDI) obtained from DLS. ${ }^{c}$ Loading capacity (LC) and encapsulation efficiency (EE) obtained from ${ }^{1} \mathrm{H}$ NMR. ${ }^{\mathrm{d}}$ Maximum micelle solubility was determined to be $100 \mathrm{~g} / \mathrm{L}$ in water, equivalent to a fulvestrant concentration of $57 \mathrm{~g} / \mathrm{L}$, which represents an $\sim 10^{9}$ fold increase in the apparent water solubility of fulvestrant $(9.53 \mathrm{ng} / \mathrm{L})$. LC and EE of PSar $100^{-}$ $b$-PLL[FLV $]_{8}{ }^{\mathrm{G} 3}$ micelles were conducted using three individually prepared samples and results are presented as mean \pm standard deviation $(\mathrm{SD})$. 
(a)
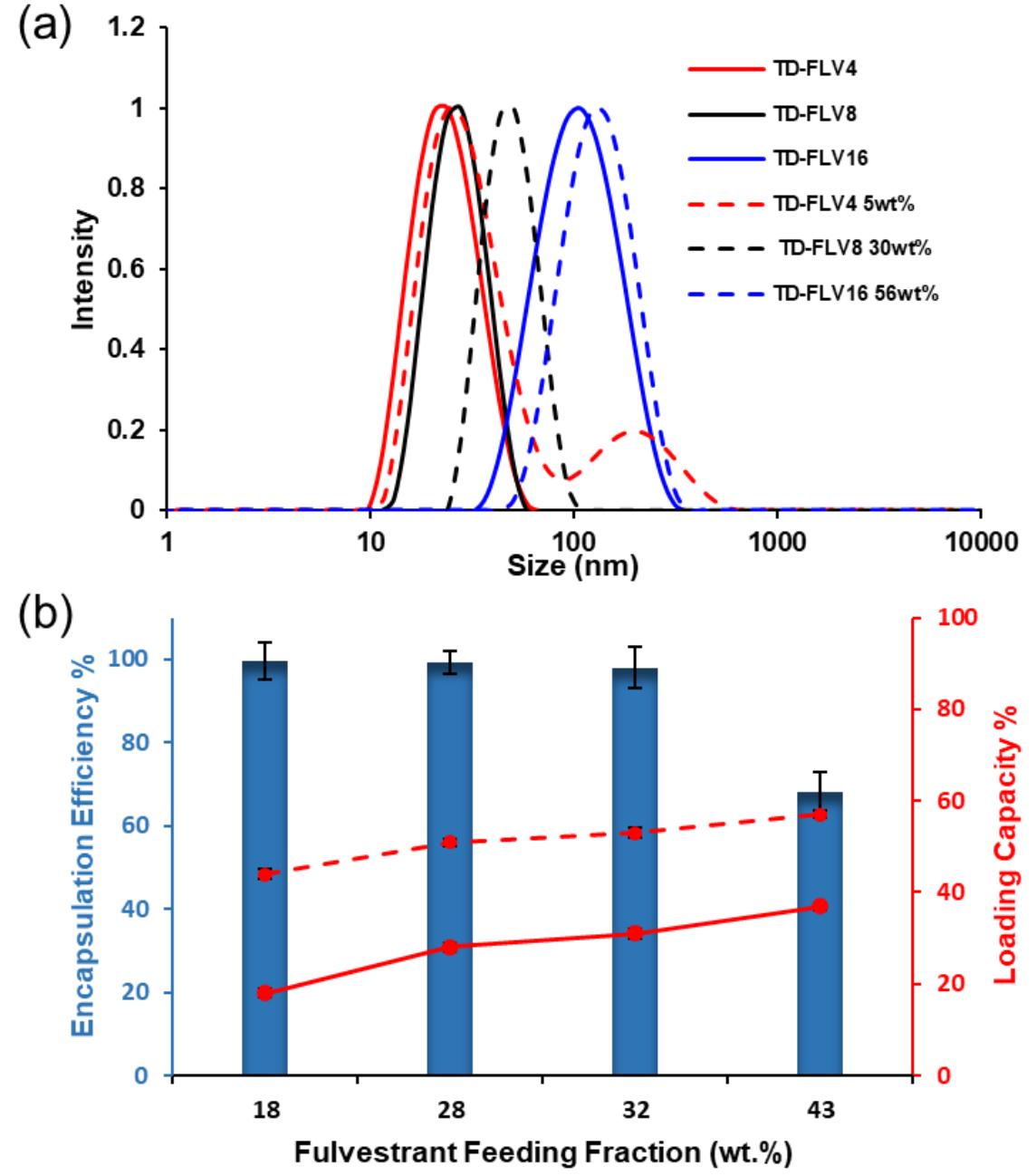

Figure 3. (a) Tuneable size ranges for micelles prepared from TD-FLV4 (red), TD-FLV8 (black), and TD-FLV16 (blue). Solid lines represent the sizes of blank micelles and dashed lines indicate the micelle size with maximum drug loading. (b) Encapsulation efficiency \% and loading capacity $\%$ of TD-FLV8 micelles at various drug feeding concentrations. Solid red line: LC\% of physically encapsulated drug, dashed red line: total fulvestrant content including both physical and covalently bound drug. Micelle concentration was kept at $20 \mathrm{mg} / \mathrm{mL}$. All the experiments were conducted using three individually prepared samples and results are presented as mean \pm standard deviation $(\mathrm{SD})$.

To the best of our knowledge, such high loading capacity and solubility improvement of a drug are rarely seen for polymer micelle nanocarriers. ${ }^{21,25,45}$ The excellent drug loading capacity of these $\mathrm{TD}-\mathrm{FLV}_{\mathrm{n}}$ micelles can be attributed to the optimized drug binding ability obtained from using a fulvestrant-conjugated telodendrimer. The broad principle 'like dissolves like' suggests that an efficient binding molecule should have similar structural motifs and conformation as the drug in order to maximize the interaction. Considering this principle, one of the strongest candidates for matching the drug must be the drug itself. 


\section{Critical micelle concentration determination}

In typical drug delivery applications, micelles will undergo extensive dilution after being injected into the bloodstream. When the concentration is below the critical micelle concentration (CMC), micelles will dissociate. As such, a stable micelle with low CMC can reduce the premature drug release caused by the destruction of micelles. ${ }^{14,46-47}$ The classic pyrene-based fluorescent probe for the determination of CMC was thought to be non-ideal for the TD-FLV micelle system as the encapsulated probes would not accurately reflect the CMC of these telodendrimer micelles without disrupting the internal structure. Therefore we chose to use a non-invasive technique such as dynamic light scattering (DLS). To determine the CMC by DLS, the scattering intensity of the TD-FLV micelle solutions as a function of concentration was measured in addition to the hydrodynamic size (Figure 4). Figure $4 \mathrm{~b}$ and $4 \mathrm{c}$ show the scattering intensities and autocorrelation functions obtained from TD-FLV8 micelle solutions of various concentrations from 0.001 to $100 \mu \mathrm{g} / \mathrm{mL}$. At concentrations below 5 $\mu \mathrm{g} / \mathrm{mL}$, the scattering intensities were found to be similar to that of PBS buffer and fluctuated slightly around $200 \mathrm{kcps}$. The correlation functions obtained had very low intercepts less than 0.1 , suggesting poor signal-to-noise ratios and no size-distribution information could be obtained, which was a clear indication these solutions contained mostly unimers. When the CMC was reached, the scattering intensity went up rapidly with increasing concentration due to the presence of large micelles formed. Using the intersection of the two slopes in Figure 4b, the CMC of TD-FLV8 micelle was calculated as $5 \mu \mathrm{g} / \mathrm{mL}(0.34 \mu \mathrm{M})$ in PBS buffer. The CMC of TD-FLV4, TD-FLV16 and fulvestrant-encapsulating (10 wt.\% and $20 \mathrm{wt} \%$ ) TD-FLV8 micelles were determined following the same method and summarized in Figure S11 and Table 3. The low CMC values of these telodendrimer micelles indicate they are thermodynamically stable and show potential for drug delivery applications.

CMCs of the TD-FLV $V_{n}$ micelles were found to be highly dependent on the telodendrimer generation and the amount of drug encapsulated. Blank micelles prepared from TD-FLV4 had a CMC of $19 \mu \mathrm{g} / \mathrm{mL}(1.8 \mu \mathrm{M})$ and TD-FLV16 micelle has a CMC of $2 \mu \mathrm{g} / \mathrm{mL}(0.11 \mu \mathrm{M})$. This significant decrease in CMC can be attributed to and increasing the number of conjugated drugs. As the telodendrimer generation went up from 2 to 4 , the number of fulvestrant attached at the dendritic block increased from 4 to 16 while the hydrophilic linear PSar remained the same length. Fulvestrant is a very hydrophobic molecule with a $\log \mathrm{P}$ of 7.67 and contains an aromatic group and multiple hydrogen bond donors/acceptors. The dendritic architecture brings all the fulvestrant hydrophobes into close proximity and thus increasing the anchoring 
effect which may also impact the observed reduction in CMC. Therefore the CMC decrease can be explained by the combination of the dendritic architecture with increasing hydrophobic interaction, $\pi-\pi$ stacking $^{48}$ and hydrogen bonding ${ }^{20}$ within the drug-conjugated block. Similarly, the same decreasing trend in CMC was also observed among the fulvestrantencapsulating micelles, where low loading (10 wt.\%) TD-FLV8 micelle showing a higher CMC $(10 \mu \mathrm{g} / \mathrm{mL})$ compared to high loading micelle (20 wt. $\%, 6 \mu \mathrm{g} / \mathrm{mL})$.

(a)

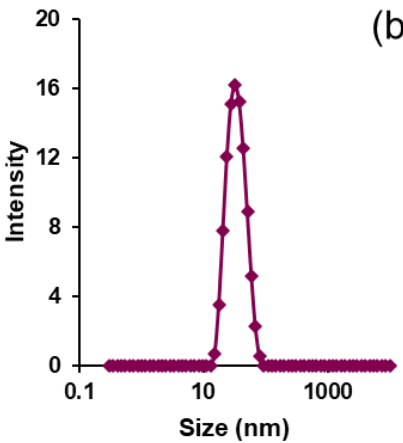

(c)

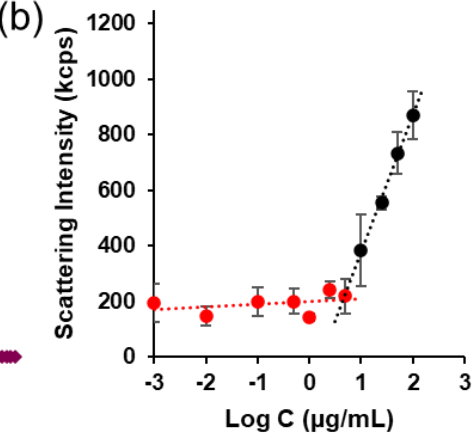

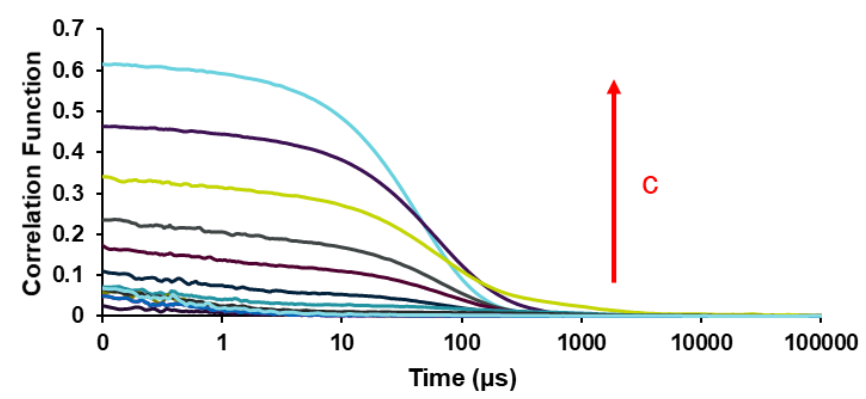

Figure 4. Characteristics of TD-FLV8 self-assembled micelles from DLS. (a) Intensity average size of $30 \mathrm{~nm}$ with PDI 0.069. Determination of CMC using (b) scattering intensity as a function of micelle mass concentration in PBS buffer. (c) Autocorrelation functions obtained at various micelle concentrations from 100 to $0.001 \mu \mathrm{g} / \mathrm{mL}$ (top to bottom).

\section{Mass photometry for characterization of telodendrimer micelles.}

Mass photometry (MP) is an optical microscopy technique based on interferometric scattering mass spectrometry (iSCAT) that measures the mass of single particles in solution. MP can detect samples with molecular weights ranging from 40 to 4,000 $\mathrm{kDa}$ with high mass accuracy $(<2 \% \text { deviation between measured and sequence mass })^{49}$ and has been used primarily for protein characterization to obtain information such as mass, stoichiometry and heterogeneity. ${ }^{50-51}$ Previously, MP has been reported to characterize PSar star polymers and the masses obtained were in good agreement with MD-SEC and MALDI-TOF-MS. ${ }^{32}$ Therefore, a similar approach was taken to measure the mass of the telodendrimer micelles and to estimate their aggregation numbers. 
(a)

TD-FLV4

(b)

TD-FLV8
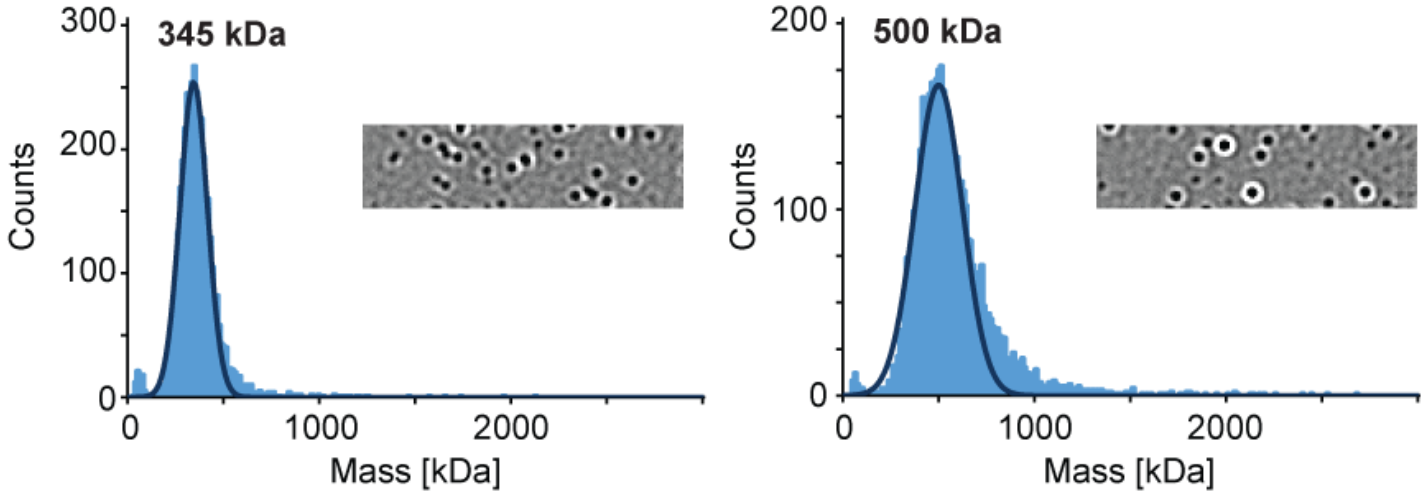

(c)

TD-FLV8 + 10wt \% FLV

(d)
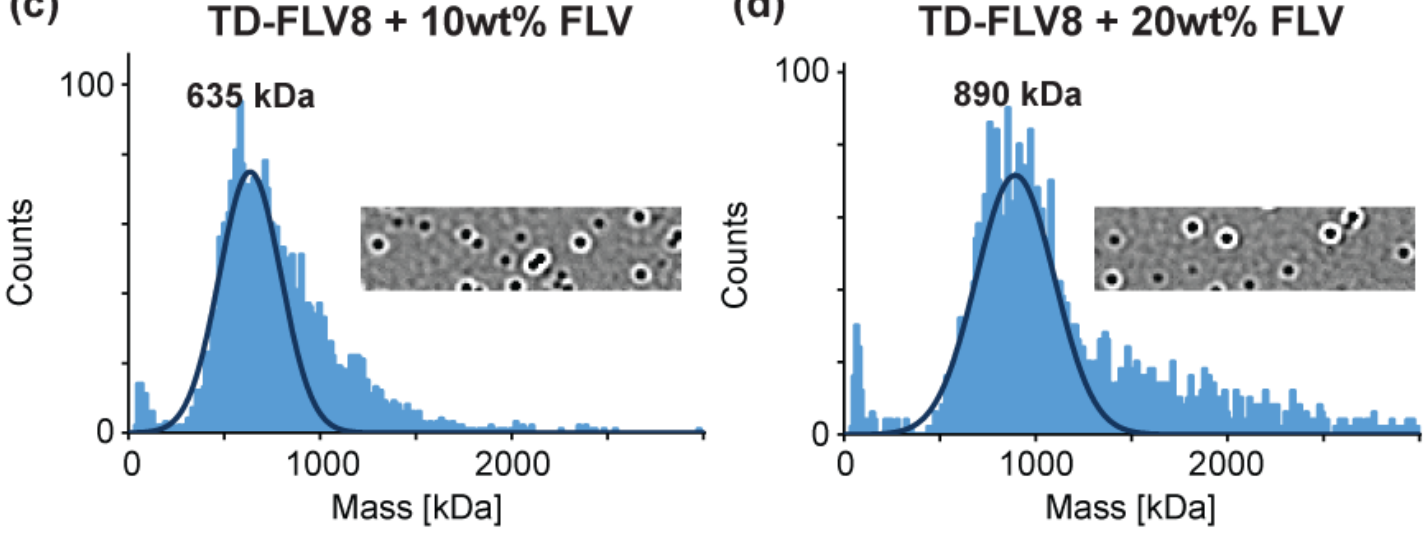

Figure 5. Mass photometry histograms showing (a) blank TD-FLV4 micelles, (b) blank TDFLV8 micelles, (c) $10 \mathrm{wt} . \%$ and (d) $20 \mathrm{wt} . \%$ fulvestrant-encapsulating TD-FLV8 micelles with representative interferometric scattering images showing the contrasts.

Table 3. Characteristics of TD-FLV $\mathrm{n}_{\mathrm{n}}$ micelles determined by DLS and Mass Photometry.

\begin{tabular}{|c|c|c|c|c|c|c|c|}
\hline Samples & MW $_{\text {telodendrimer }}$ & LC \% & $\begin{array}{c}\mathrm{CMC} \\
(\mathrm{\mu g} / \mathrm{mL})\end{array}$ & $\begin{array}{c}\text { Molar } \\
\text { massmicelle }\end{array}$ & $N_{\text {agg }}$ & $\begin{array}{c}\text { \# of } \\
\text { encapsulated } \\
\text { drugs per } \\
\text { micelle }\end{array}$ & $\begin{array}{c}\text { total \# of } \\
\text { drugs per } \\
\text { micelle }\end{array}$ \\
\hline TD-FLV4 $^{\mathbf{c}}$ & $10.3 \mathrm{kDa}$ & - & 18.6 & $345 \mathrm{kDa}$ & 34 & 0 & 140 \\
\hline TD-FLV8 $^{\mathbf{c}}$ & $13.3 \mathrm{kDa}$ & - & 4.57 & $500 \mathrm{kDa}$ & 38 & 0 & 300 \\
\hline $\begin{array}{c}\text { TD- } \\
\text { FLV16 }^{c}\end{array}$ & $20.3 \mathrm{kDa}$ & - & 2.14 & $\mathrm{NC}$ & $\mathrm{NC}$ & $\mathrm{NC}$ & $\mathrm{NC}$ \\
\hline $\begin{array}{c}\text { TD- } \\
\text { FLV8a }^{\mathbf{d}}\end{array}$ & - & 12 & 9.55 & $635 \mathrm{kDa}$ & 43 & 110 & 450 \\
\hline $\begin{array}{c}\text { TD- } \\
\text { FLV8b }^{\mathbf{d}}\end{array}$ & - & 23 & 5.75 & $890 \mathrm{kDa}$ & 54 & 300 & 730 \\
\hline
\end{tabular}

${ }^{a}$ CMC determined from DLS. ${ }^{b}$ Calculated micelle molar mass from mass photometry. NC Not calculated - particle size beyond limit of MP instrumentation. ${ }^{c}$ Blank micelles with no encapsulated drugs. ${ }^{d}$ Drug-encapsulating micelles with $10 \mathrm{wt} . \%$ fulvestrant (size $=35 \pm 0.4$ $\mathrm{nm}, \mathrm{PDI}=0.14$ ) and $20 \mathrm{wt} . \%$ fulvestrant (size $=40 \pm 0.5 \mathrm{~nm}, \mathrm{PDI}=0.13$ ), respectively. 
Blank micelles of TD-FLV $(n=4,8,16)$ and two fulvestrant-solubilizing (10 wt.\% and 20 wt.\%) TD-FLV8 micelles were examined by MP and the results obtained summarized in Table 3. Fitting the histograms with Gaussian fits, the average mass of the TD-FLV4 micelle was determined to be $345 \mathrm{kDa}$, from which we derive an aggregation number $\left(N_{\mathrm{agg}}\right)$ of 34 telodendrimer unimers. For TD-FLV8 micelle, a MW of $500 \mathrm{kDa}$ with $N_{\mathrm{agg}}$ of 38 was obtained, which is in agreement with the increased micelle size determined from DLS. Two fulvestrantencapsulating TD-FLV8 micelles were measured and analysed similarly. The representative interferometric scattering images in Figure 5 shows that the contrast of these four samples increased as micelle molecular weight increased. Unfortunately, TD-FLV16 micelle with a size of $116 \mathrm{~nm}$ was too large and beyond the MP working mass range, therefore we were unable to obtain any useful information. The high loading capacity of these telodendrimer micelles was reflected by the total number of drugs per micelle, where a single TD-FLV8 micelle could carry up to 730 fulvestrant molecules.

\section{Colloidal stability of telodendrimer micelles}

The physical stability of TD-FLV8 telodendrimer micelles stored at $4{ }^{\circ} \mathrm{C}$ in DI water with various amount of fulvestrant encapsulated was monitored by DLS over a period of one month (Figure S12). No significant increase in the size and PDI of the micelles was observed, indicating good colloidal stability and no micelle agglomeration.

\section{In vitro release of fulvestrant from telodendrimer micelles.}

In our design, the fulvestrant was conjugated to the telodendrimers via an ester linker, providing a site for hydrolytic cleavage. To demonstrate drug could be released in a controlled manner, the hydrolysis of the TD-FLV8 micelle was monitored at $37^{\circ} \mathrm{C}$ up to 1 week at $\mathrm{pH}$ 8.5, 7.4 and 5.5. The amount of drug released was quantified using UPLC. As shown in Figure 6, the release of fulvestrant from blank TD-FLV8 micelles after $24 \mathrm{~h}$ at $\mathrm{pH} 8.5, \mathrm{pH} 7.4$ and $\mathrm{pH}$ 5.5 was $52.8 \%, 21.2 \%$ and $1.3 \%$, respectively. As expected for an ester linkage to the fulvestrant molecule, the bond was hydrolyzed very quickly at basic $\mathrm{pH}$ compared to neutral and $\mathrm{pH} 5.5$ the latter where less than $10 \%$ drug was released after $168 \mathrm{~h}$. The presence of protein can impact release rate by disrupting micelle structures. ${ }^{52}$ To evaluate the effect of protein binding in vitro, the hydrolysis of TD-FLV8 micelles was also monitored at pH 7.4 in the presence of $45 \mathrm{mg} / \mathrm{mL}$ bovine serum albumin (BSA). Interestingly, the hydrolysis rate was very close to the one obtained in the absence of the protein, indicating the presence of BSA did not accelerate the release rate and suggesting protein binding did not interfere with the micellar structure owing to the stealth PSar corona and the high micelle stability. 


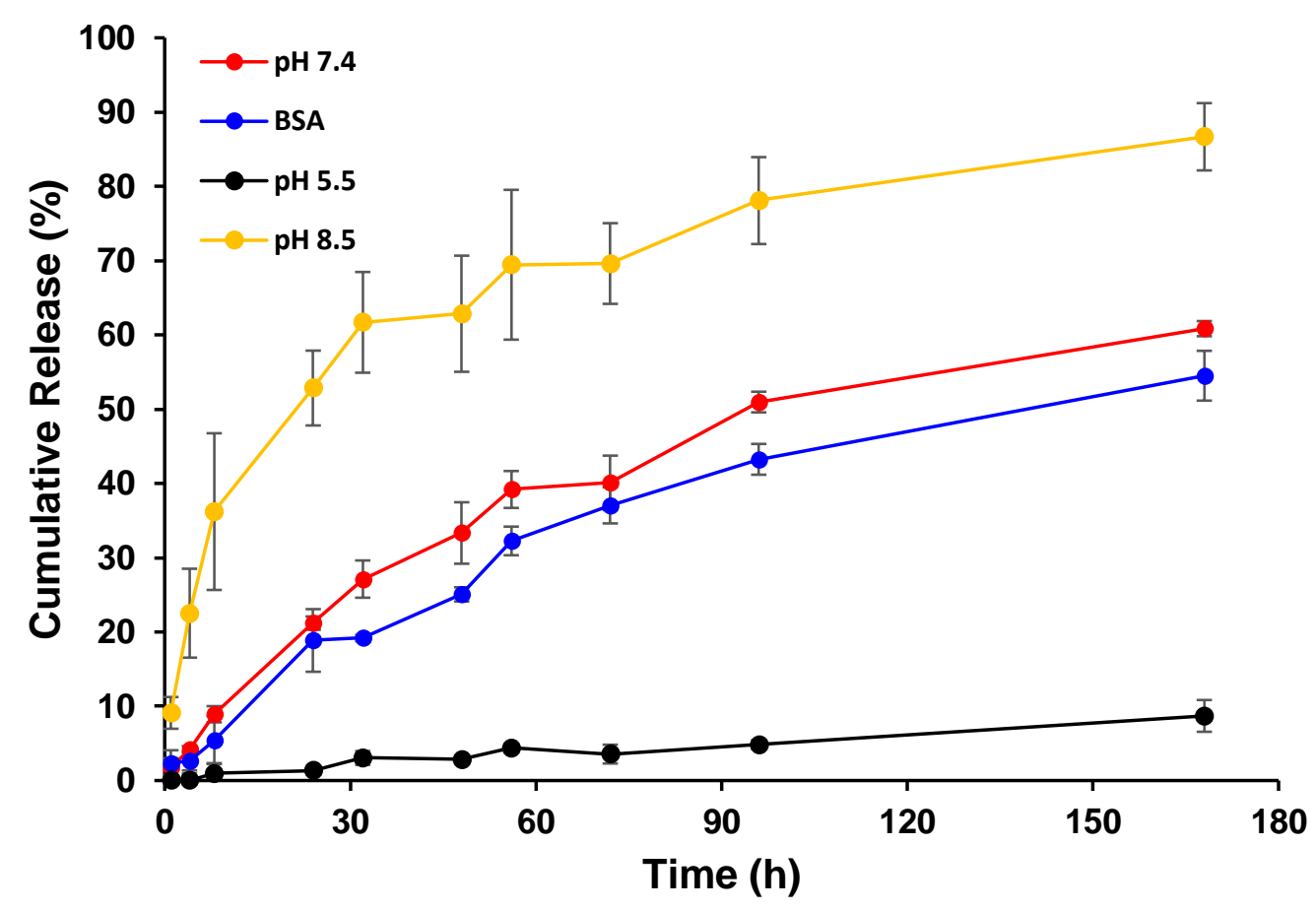

Figure 6. In vitro drug release profile of blank TD-FLV8 micelles at (a) $\mathrm{pH} 7.4$, (b) pH 7.4 in

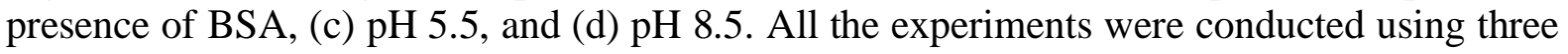
individually prepared samples and results are presented as mean \pm standard deviation (SD).

\section{Conclusion}

In summary, we reported the synthesis of a poly(sarcosine)-b-poly(L-lysine) telodendrimer PSar ${ }_{100}-\mathrm{b}-\mathrm{PLL}[\mathrm{FLV}]_{\mathrm{n}}{ }^{\mathrm{Gm}}$ in which $n$ represents the number of fulvestrant molecules covalently attached at the periphery of the dendritic block, and $\mathrm{G}_{\mathrm{m}}$ represents the lysine dendron generations 2-4. The telodendrimer was synthesized by polymerization of a linear PSar chain and divergent growth of a lysine dendron from the PSar chain terminal amine. The terminal amine groups of the lysine dendron were used to attach fulvestrant using a succinic acid linker. Self-assembly experiments showed all three telodendrimers TD-FLV4, TD-FLV8, and TD-FLV16 formed self-assemblies in water using a co-solvent evaporation method. The generation of telodendrimers and therefore the number of fulvestrant molecules on the dendritic block, strongly influenced the micelle physicochemical properties such as size, stability, and additional encapsulated drug loading capacity. A novel technique to the field, mass photometry was employed to estimate the number of unimers in the micelles and therefore the numbers of drug molecule/micelle in a facile way. From the different telodendrimers synthesized, the TD-FLV8 micelles exhibited the most tuneable sizes between 30-60 nm and high drug load of $\sim 55$ wt.\% (combining conjugated and encapsulated drug), in combination 
with excellent colloidal stability and high water solubility making them the most suitable candidate for the delivery of fulvestrant. We believe that the versatility of these telodendrimerbased micelle systems to both conjugate and encapsulate drug with high efficiency and stability, in addition to having other tuneable properties makes them a promising drug delivery system for a range of active pharmaceutical ingredients and therapeutic targets. 


\section{Reference}

1. $\quad$ Peer, D.; Karp, J. M.; Hong, S.; Farokhzad, O. C.; Margalit, R.; Langer, R., Nanocarriers as an emerging platform for cancer therapy. Nat Nanotechnol 2007, 2 (12), 751760.

2. Matsumura, Y.; Kataoka, K., Preclinical and clinical studies of anticancer agentincorporating polymer micelles. Cancer Sci 2009, 100 (4), 572-579.

3. Ghosh, B.; Biswas, S., Polymeric micelles in cancer therapy: State of the art. $J$ Control Release 2021, 332, 127-147.

4. Leroux, J. C., Editorial: Drug Delivery: Too Much Complexity, Not Enough Reproducibility? Angew Chem Int Ed Engl 2017, 56 (48), 15170-15171.

5. Luxenhofer, R., Polymers and nanomedicine: considerations on variability and reproducibility when combining complex systems. Nanomedicine (Lond) 2015, 10 (20), 3109-3119.

6. Kim, S.; Shi, Y.; Kim, J. Y.; Park, K.; Cheng, J. X., Overcoming the barriers in micellar drug delivery: loading efficiency, in vivo stability, and micelle-cell interaction. Expert Opin Drug Deliv 2010, 7 (1), 49-62.

7. $\quad$ Zhang, Y.; Ren, T.; Gou, J.; Zhang, L.; Tao, X.; Tian, B.; Tian, P.; Yu, D.; Song, J.; Liu, X.; Chao, Y.; Xiao, W.; Tang, X., Strategies for improving the payload of small molecular drugs in polymeric micelles. J Control Release 2017, 261, 352-366.

8. Kaga, S.; Truong, N. P.; Esser, L.; Senyschyn, D.; Sanyal, A.; Sanyal, R.; Quinn, J. F.; Davis, T. P.; Kaminskas, L. M.; Whittaker, M. R., Influence of Size and Shape on the Biodistribution of Nanoparticles Prepared by Polymerization-Induced Self-Assembly. Biomacromolecules 2017, 18 (12), 3963-3970.

9. Chithrani, B. D.; Ghazani, A. A.; Chan, W. C., Determining the size and shape dependence of gold nanoparticle uptake into mammalian cells. Nano Lett 2006, 6 (4), $662-$ 668.

10. Albanese, A.; Tang, P. S.; Chan, W. C., The effect of nanoparticle size, shape, and surface chemistry on biological systems. Annu Rev Biomed Eng 2012, 14, 1-16.

11. Venkataraman, S.; Hedrick, J. L.; Ong, Z. Y.; Yang, C.; Ee, P. L.; Hammond, P. T.; Yang, Y. Y., The effects of polymeric nanostructure shape on drug delivery. Adv Drug Deliv Rev 2011, 63 (14-15), 1228-1246.

12. Wang, Z.; Deng, X.; Ding, J.; Zhou, W.; Zheng, X.; Tang, G., Mechanisms of drug release in $\mathrm{pH}$-sensitive micelles for tumour targeted drug delivery system: A review. Int $J$ Pharm 2018, 535 (1-2), 253-260.

13. Ahmad, Z.; Shah, A.; Siddiq, M.; Kraatz, H.-B., Polymeric micelles as drug delivery vehicles. RSC Adv. 2014, 4 (33), 17028-17038.

14. Owen, S. C.; Chan, D. P. Y.; Shoichet, M. S., Polymeric micelle stability. Nano Today 2012, 7 (1), 53-65.

15. Kozlov, M. Y.; Melik-Nubarov, N. S.; Batrakova, E. V.; Kabanov, A. V., Relationship between Pluronic Block Copolymer Structure, Critical Micellization Concentration and Partitioning Coefficients of Low Molecular Mass Solutes.

Macromolecules 2000, 33 (9), 3305-3313.

16. Adams, M. L.; Kwon, G. S., Relative aggregation state and hemolytic activity of amphotericin B encapsulated by poly(ethylene oxide)-block-poly(N-hexyl-l-aspartamide)acyl conjugate micelles: effects of acyl chain length. Journal of Controlled Release 2003, 87 (1-3), 23-32.

17. Adams, M. L.; Kwon, G. S., The effects of acyl chain length on the micelle properties of poly(ethylene oxide)-block-poly(N-hexyl-L-aspartamide)-acyl conjugates. J Biomater Sci Polym Ed 2002, 13 (9), 991-1006. 
18. Van Domeselaar, G. H.; Kwon, G. S.; Andrew, L. C.; Wishart, D. S., Application of solid phase peptide synthesis to engineering PEO-peptide block copolymers for drug delivery. Colloids and Surfaces B: Biointerfaces 2003, 30 (4), 323-334.

19. Cabral, H.; Kataoka, K., Progress of drug-loaded polymeric micelles into clinical studies. J Control Release 2014, 190, 465-476.

20. Kim, S. H.; Tan, J. P.; Nederberg, F.; Fukushima, K.; Colson, J.; Yang, C.; Nelson, A.; Yang, Y. Y.; Hedrick, J. L., Hydrogen bonding-enhanced micelle assemblies for drug delivery. Biomaterials 2010, 31 (31), 8063-8071.

21. Lv, S.; Wu, Y.; Cai, K.; He, H.; Li, Y.; Lan, M.; Chen, X.; Cheng, J.; Yin, L., High Drug Loading and Sub-Quantitative Loading Efficiency of Polymeric Micelles Driven by Donor-Receptor Coordination Interactions. J Am Chem Soc 2018, 140 (4), 1235-1238.

22. Aliabadi, H. M.; Lavasanifar, A., Polymeric micelles for drug delivery. Expert Opin Drug Deliv 2006, 3 (1), 139-162.

23. Lübtow, M. M.; Hahn, L.; Haider, M. S.; Luxenhofer, R., Drug Specificity, Synergy and Antagonism in Ultrahigh Capacity Poly(2-oxazoline)/Poly(2-oxazine) based Formulations. J Am Chem Soc 2017, 139 (32), 10980-10983.

24. Lübtow, M. M.; Haider, M. S.; Kirsch, M.; Klisch, S.; Luxenhofer, R., Like Dissolves Like? A Comprehensive Evaluation of Partial Solubility Parameters to Predict Polymer-Drug Compatibility in Ultrahigh Drug-Loaded Polymer Micelles. Biomacromolecules 2019, 20 (8), 3041-3056.

25. He, Z.; Wan, X.; Schulz, A.; Bludau, H.; Dobrovolskaia, M. A.; Stern, S. T.; Montgomery, S. A.; Yuan, H.; Li, Z.; Alakhova, D.; Sokolsky, M.; Darr, D. B.; Perou, C. M.; Jordan, R.; Luxenhofer, R.; Kabanov, A. V., A high capacity polymeric micelle of paclitaxel: Implication of high dose drug therapy to safety and in vivo anti-cancer activity. Biomaterials 2016, 101, 296-309.

26. Lübtow, M. M.; Nelke, L. C.; Seifert, J.; Kuhnemundt, J.; Sahay, G.; Dandekar, G.; Nietzer, S. L.; Luxenhofer, R., Drug induced micellization into ultra-high capacity and stable curcumin nanoformulations: Physico-chemical characterization and evaluation in 2D and 3D in vitro models. J Control Release 2019, 303, 162-180.

27. Mikhail, A. S.; Allen, C., Poly(ethylene glycol)-b-poly(epsilon-caprolactone) micelles containing chemically conjugated and physically entrapped docetaxel: synthesis, characterization, and the influence of the drug on micelle morphology. Biomacromolecules 2010, 11 (5), 1273-1280.

28. Shi, C.; Guo, D.; Xiao, K.; Wang, X.; Wang, L.; Luo, J., A drug-specific nanocarrier design for efficient anticancer therapy. Nat Commun 2015, 6, 1-14.

29. Huang, W.; Wang, X.; Shi, C.; Guo, D.; Xu, G.; Wang, L.; Bodman, A.; Luo, J., Finetuning vitamin E-containing telodendrimers for efficient delivery of gambogic acid in colon cancer treatment. Mol Pharm 2015, 12 (4), 1216-1229.

30. Moquin, A.; Sturn, J.; Zhang, I.; Ji, J.; von Celsing, R.; Vali, H.; Maysinger, D.; Kakkar, A., Unraveling Aqueous Self-Assembly of Telodendrimers to Shed Light on Their Efficacy in Drug Encapsulation. ACS Applied Bio Materials 2019, 2 (10), 4515-4526.

31. Raw, S. A., An improved process for the synthesis of DMTMM-based coupling reagents. Tetrahedron Letters 2009, 50 (8), 946-948.

32. England, R. M.; Moss, J. I.; Gunnarsson, A.; Parker, J. S.; Ashford, M. B., Synthesis and Characterization of Dendrimer-Based Polysarcosine Star Polymers: Well-Defined, Versatile Platforms Designed for Drug-Delivery Applications. Biomacromolecules 2020, 21 (8), 3332-3341.

33. Wurm, F.; Frey, H., Linear-dendritic block copolymers: The state of the art and exciting perspectives. Progress in Polymer Science 2011, 36 (1), 1-52. 
34. Xiao, K.; Luo, J.; Fowler, W. L.; Li, Y.; Lee, J. S.; Xing, L.; Cheng, R. H.; Wang, L.; Lam, K. S., A self-assembling nanoparticle for paclitaxel delivery in ovarian cancer.

Biomaterials 2009, 30 (30), 6006-6016.

35. Robertson, J. F.; Harrison, M., Fulvestrant: pharmacokinetics and pharmacology. $\mathrm{Br} \mathrm{J}$ Cancer 2004, 90 Suppl 1, S7-10.

36. Weber, B.; Birke, A.; Fischer, K.; Schmidt, M.; Barz, M., Solution Properties of Polysarcosine: From Absolute and Relative Molar Mass Determinations to Complement Activation. Macromolecules 2018, 51 (7), 2653-2661.

37. Birke, A.; Ling, J.; Barz, M., Polysarcosine-containing copolymers: Synthesis, characterization, self-assembly, and applications. Progress in Polymer Science 2018, 81, 163208.

38. Son, K.; Ueda, M.; Taguchi, K.; Maruyama, T.; Takeoka, S.; Ito, Y., Evasion of the accelerated blood clearance phenomenon by polysarcosine coating of liposomes. J Control Release 2020, 322, 209-216.

39. Nogueira, S. S.; Schlegel, A.; Maxeiner, K.; Weber, B.; Barz, M.; Schroer, M. A.; Blanchet, C. E.; Svergun, D. I.; Ramishetti, S.; Peer, D.; Langguth, P.; Sahin, U.; Haas, H., Polysarcosine-Functionalized Lipid Nanoparticles for Therapeutic mRNA Delivery. ACS Applied Nano Materials 2020, 3 (11), 10634-10645.

40. Cheng, L.; Cao, D., Effect of tail architecture on self-assembly of amphiphiles for polymeric micelles. Langmuir 2009, 25 (5), 2749-2756.

41. Cheng, C.-C.; Sun, Y.-T.; Lee, A.-W.; Huang, S.-Y.; Fan, W.-L.; Chiao, Y.-H.; Chiu, C.-W.; Lai, J.-Y., Hydrogen-bonded supramolecular micelle-mediated drug delivery enhances the efficacy and safety of cancer chemotherapy. Polymer Chemistry 2020, 11 (16), 2791-2798.

42. Luxenhofer, R.; Schulz, A.; Roques, C.; Li, S.; Bronich, T. K.; Batrakova, E. V.; Jordan, R.; Kabanov, A. V., Doubly amphiphilic poly(2-oxazoline)s as high-capacity delivery systems for hydrophobic drugs. Biomaterials 2010, 31 (18), 4972-4979.

43. Haider, M. S.; Lübtow, M. M.; Endres, S.; Forster, S.; Flegler, V. J.; Bottcher, B.; Aseyev, V.; Poppler, A. C.; Luxenhofer, R., Think Beyond the Core: Impact of the Hydrophilic Corona on Drug Solubilization Using Polymer Micelles. ACS Appl Mater Interfaces 2020, 12 (22), 24531-24543.

44. National Center for Biotechnology Information (2021). PubChem Compound Summary for CID 104741, Fulvestrant. . https://pubchem.ncbi.nlm.nih.gov/compound/Fulvestrant. (accessed May 24).

45. Shen, S.; Wu, Y.; Liu, Y.; Wu, D., High drug-loading nanomedicines: progress, current status, and prospects. Int J Nanomedicine 2017, 12, 4085-4109.

46. Shi, Y.; Lammers, T.; Storm, G.; Hennink, W. E., Physico-Chemical Strategies to Enhance Stability and Drug Retention of Polymeric Micelles for Tumor-Targeted Drug Delivery. Macromol Biosci 2017, 17 (1), 1600160.

47. Lu, Y.; Zhang, E.; Yang, J.; Cao, Z., Strategies to improve micelle stability for drug delivery. Nano Res 2018, 11 (10), 4985-4998.

48. Shi, Y.; van Steenbergen, M. J.; Teunissen, E. A.; Novo, L.; Gradmann, S.; Baldus, M.; van Nostrum, C. F.; Hennink, W. E., Pi-pi stacking increases the stability and loading capacity of thermosensitive polymeric micelles for chemotherapeutic drugs.

Biomacromolecules 2013, 14 (6), 1826-1837.

49. Young, G.; Hundt, N.; Cole, D.; Fineberg, A.; Andrecka, J.; Tyler, A.; Olerinyova, A.; Ansari, A.; Marklund, E. G.; Collier, M. P.; Chandler, S. A.; Tkachenko, O.; Allen, J.; Crispin, M.; Billington, N.; Takagi, Y.; Sellers, J. R.; Eichmann, C.; Selenko, P.; Frey, L.; Riek, R.; Galpin, M. R.; Struwe, W. B.; Benesch, J. L. P.; Kukura, P., Quantitative mass imaging of single biological macromolecules. Science 2018, 360 (6387), 423-427. 
50. Sonn-Segev, A.; Belacic, K.; Bodrug, T.; Young, G.; VanderLinden, R. T.; Schulman, B. A.; Schimpf, J.; Friedrich, T.; Dip, P. V.; Schwartz, T. U.; Bauer, B.; Peters, J. M.; Struwe, W. B.; Benesch, J. L. P.; Brown, N. G.; Haselbach, D.; Kukura, P., Quantifying the heterogeneity of macromolecular machines by mass photometry. Nat Commun 2020, 11 (1), 1772-1781.

51. Olerinyova, A.; Sonn-Segev, A.; Gault, J.; Eichmann, C.; Schimpf, J.; Kopf, A. H.; Rudden, L. S. P.; Ashkinadze, D.; Bomba, R.; Frey, L.; Greenwald, J.; Degiacomi, M. T.; Steinhilper, R.; Killian, J. A.; Friedrich, T.; Riek, R.; Struwe, W. B.; Kukura, P., Mass Photometry of Membrane Proteins. Chem 2020.

52. Lu, J.; Owen, S. C.; Shoichet, M. S., Stability of Self-Assembled Polymeric Micelles in Serum. Macromolecules 2011, 44 (15), 6002-6008. 